\title{
Transport of Gaseous Hydrogen Peroxide and Ozone into Bulk Water vs. Electrosprayed Aerosol
}

\author{
Mostafa Elsayed Hassan (D), Mário Janda *(D) and Zdenko Machala *(D) \\ Division of Environmental Physics, Faculty of Mathematics, Physics and Informatics, Comenius University, \\ Mlynská Dolina, 84248 Bratislava, Slovakia; mostafa.hassan@fmph.uniba.sk \\ * Correspondence: mario.janda@fmph.uniba.sk (M.J.); machala@fmph.uniba.sk (Z.M.)
}

check for updates

Citation: Hassan, M.E.; Janda, M.; Machala, Z. Transport of Gaseous Hydrogen Peroxide and Ozone into Bulk Water vs. Electrosprayed Aerosol. Water 2021, 13, 182. https:/ / doi.org/10.3390/w13020182

Received: 30 November 2020 Accepted: 10 January 2021 Published: 14 January 2021

Publisher's Note: MDPI stays neutral with regard to jurisdictional clai$\mathrm{ms}$ in published maps and institutional affiliations.

Copyright: (C) 2021 by the authors. Licensee MDPI, Basel, Switzerland. This article is an open access article distributed under the terms and conditions of the Creative Commons Attribution (CC BY) license (https:// creativecommons.org/licenses/by/ $4.0 /)$.

\begin{abstract}
Production and transport of reactive species through plasma-liquid interactions play a significant role in multiple applications in biomedicine, environment, and agriculture. Experimental investigations of the transport mechanisms of typical air plasma species: hydrogen peroxide $\left(\mathrm{H}_{2} \mathrm{O}_{2}\right)$ and ozone $\left(\mathrm{O}_{3}\right)$ into water are presented. Solvation of gaseous $\mathrm{H}_{2} \mathrm{O}_{2}$ and $\mathrm{O}_{3}$ from an airflow into water bulk vs. electrosprayed microdroplets was measured, while changing the water flow rate and applied voltage, during different treatment times and gas flow rates. The solvation rate of $\mathrm{H}_{2} \mathrm{O}_{2}$ and $\mathrm{O}_{3}$ increased with the treatment time and the gas-liquid interface area. The total surface area of the electrosprayed microdroplets was larger than that of the bulk, but their lifetime was much shorter. We estimated that only microdroplets with diameters below $\sim 40 \mu \mathrm{m}$ could achieve the saturation by $\mathrm{O}_{3}$ during their lifetime, while the saturation by $\mathrm{H}_{2} \mathrm{O}_{2}$ was unreachable due to its depletion from air. In addition to the short-lived flying microdroplets, the longer-lived bottom microdroplets substantially contributed to $\mathrm{H}_{2} \mathrm{O}_{2}$ and $\mathrm{O}_{3}$ solvation in water electrospray. This study contributes to a better understanding of the gaseous $\mathrm{H}_{2} \mathrm{O}_{2}$ and $\mathrm{O}_{3}$ transport into water and will lead to design optimization of the water spray and plasma-liquid interaction systems.
\end{abstract}

Keywords: plasma-liquid interactions; water electrospray; aerosol microdroplet; bulk water; plasmaactivated water; Henry's law solubility; ozone; hydrogen peroxide

\section{Introduction}

Interactions of non-equilibrium plasmas with liquids, known as plasma-liquid interactions [1-3], have become an emerging topic in the field of plasma science and technology, which contributed to many applications, ranging from environmental remediation $[4,5]$ to material science [6], and health care $[7,8]$. The plasma interactions with liquids are of great importance in a plethora of various plasma-liquid systems because the liquid properties change in time under the interaction with plasma, and vice-versa [9]. The distinctive characteristics of non-equilibrium (cold) atmospheric plasmas, which are often created in ambient air, lead to a broad extension of their use in various biomedical applications [10-15]. Cold plasmas can be effective tools for microbial decontamination and sterilization [16], interact with living tissues [17], treat mammalian and cancerous cells [18], induce blood coagulation [16,19], can be applied in wound healing [20] and dentistry [21], and can be successfully transferred into clinical practice $[14,15,22]$. Novel applications in water cleaning, food production, and agriculture (e.g., seed germination and plant growth promotion, and pest control) without causing undesired side-effects or environmental burdens are on their way [23-26].

Atmospheric air plasmas in contact with liquid water or aqueous solutions generate "plasma-activated water" (PAW), which contains various reactive oxygen and nitrogen species (RONS), e.g., hydrogen peroxide $\left(\mathrm{H}_{2} \mathrm{O}_{2}\right)$, nitrate $\left(\mathrm{NO}_{3}{ }^{-}\right)$and nitrite $\left(\mathrm{NO}_{2}{ }^{-}\right)$anions, ozone $\left(\mathrm{O}_{3}\right)$, as well as other short-lived reactive species [23,27-29]. It has been reported by many research groups that these PAW solutions are effective in killing microbes and 
inactivating cancer cells [28,30-32]. PAW and other plasma-activated water solutions are examples of the outcome of plasma-liquid interactions, where the plasma RONS are transported/dissolved into water.

Species transport through the gas-liquid interface can be conceptualized by the change in density across the interface. This transition occurs over a few nanometers or less. The rough interface has fluctuations with water exchanging from the bulk to the boundary over several picoseconds [3]. Water considered as a model system in molecular dynamics simulations provided an atomic-level insight into the plasma-liquid film interaction mechanisms. It was found that plasma generated $\mathrm{H}_{2} \mathrm{O}_{2}$ species can travel through the water interface layer during $1.4 \mathrm{~ns}$, penetrate deeper, and eventually reach the surface of biomolecules [33].

The plasma-liquid interface area is a key parameter maximizing the contact between the plasma and the treated water solution, thus determining the obtained plasma chemical effects [34]. Regarding typical long-lived plasma oxidizing species, $\mathrm{H}_{2} \mathrm{O}_{2}$, and its formation in multiple plasma-water systems has been extensively studied over the last decades. In a review by Locke et al., the formation of $\mathrm{H}_{2} \mathrm{O}_{2}$ was investigated in various plasma reactors with discharges directly in and over the liquid water with bubbles, and capillary discharges, in terms of $\mathrm{H}_{2} \mathrm{O}_{2}$ gas-liquid mass transfer characteristics. The highest $\mathrm{H}_{2} \mathrm{O}_{2}$ yields were found for the water droplet spray which provides large surface areas and small length scales to enhance the mass transfer rates [35]. Corona discharges yielded $\mathrm{H}_{2} \mathrm{O}_{2}$ production very similar to the other gas plasma reactors over water [36]. With a rising $\mathrm{H}_{2} \mathrm{O}_{2}$ amount in the gas phase, the aqueous $\mathrm{H}_{2} \mathrm{O}_{2}$ concentration increased whether $\mathrm{H}_{2} \mathrm{O}_{2}$ was created by the plasma in the gas phase or by the $\mathrm{H}_{2} \mathrm{O}_{2}$ bubbler (without plasma), with a slightly higher liquid $\mathrm{H}_{2} \mathrm{O}_{2}$ concentration for the plasma case [37]. Gaseous $\mathrm{H}_{2} \mathrm{O}_{2}$ produced near the air plasma-liquid water interface shows an extremely fast dissolution through this gas-liquid interface, as was demonstrated in the earlier study [31].

Transformation of bulk water into fine droplets or aerosol results in an increasing surface-to-volume ratio and thus accelerates the transport of RONS into the water, which is of vital importance for slowly soluble species, such as ozone. This concept has been adopted by several research groups [38-41], as well as our previous work [31,32,42]. For instance, in two different cold air plasma sources (streamer corona and transient spark discharge), PAW was prepared by the electrospray of fine aerosol droplets directly through the active plasma zone, which resulted in a very efficient transfer of gaseous RONS into water.

The enhanced transport of ozone into the water is of particular interest in the commercially used ozonation process that has become a common disinfection method for drinking water treatment due to its powerful oxidizing capacity and its ability to be applied at different stages throughout the treatment plant [43]. Mass transfer of ozone into the liquid water is considered one of the most important stages in the ozone oxidation technology to eliminate organic water contaminants [44]. The mass transport characteristics of $\mathrm{O}_{3}$ to the bulk water can be improved through non-porous membranes [45]. Wastewater treatment by ozone micro-nano-bubbles of sizes from tens of nanometers to tens of micrometers also leads to an enhancement of the surface-to-volume ratio, in a similar concept as by water aerosolization studied in this manuscript. The mass transfer efficiency of ozone to water was enhanced and controlled by the quantity and size of these ozone micro-nano-bubbles [46].

Electrospray (ES) or electrohydrodynamic atomization of liquids is one of the very efficient ways of producing liquid aerosols. It occurs from a conical meniscus located at the end of a capillary tube (nozzle) continuously supplied with liquid under the influence of a strong electric field. Positive and negative charges separate inside the liquid droplets, and charges of the same polarity as the nozzle, move towards the droplet surface, inducing a surface charge density on the liquid surface. The charged droplets generated from the nozzle of the high electric potential have different sizes ranging from large $(\mathrm{mm})$ to very small (nm) droplets, at various droplet populations from polydisperse to monodisperse, at 
different flow rates, where the droplet diameter is controlled by varying the ES flow rate or the electrical conductivity of the liquid [47-49].

There are many parameters involved in the ES process, which determine different modes of continuous and intermittent ES, producing aerosols of highly varied characteristics. The key parameters are the geometry of the system used, the applied voltage, the dielectric strength of the ambient medium, the liquid flow rate, and the physical properties of the liquid, such as its electrical conductivity, surface tension, and viscosity. Due to the high electrical potential and low radii of the capillary nozzle, water meniscus, and the liquid jet at the nozzle outlet, the electric field is often sufficiently high to cause ionization processes in the surrounding gas. Corona discharge occurs at a low discharge power around the sharp edges of the nozzle where the electric field is locally applied [50]. The lifetime of the sub-micrometer liquid aerosol droplets (a few milliseconds) in cold atmospheric (corona) plasmas, is sufficient to produce many chemical reactions in the liquid aerosol [51].

Coupling of plasma-liquid interactions to the liquid ES with plasma-induced chemical processes has many technical advantages, as it employs the same device and the same high voltage power supply applied to the capillary nozzle. In addition, this configuration enables the efficient mass transfer of active species produced by plasma into the water droplets due to their micrometer-scale dimensions with a large surface-area-to-volume ratio [52]. The interest and applications of water ES for the liquid sprays have been applied to various areas due to their low cost, environment-friendly, and biocompatible water treatment [53].

Stancampiano et al. in their review conclude that plasma-aerosol droplets act as efficient microreactors where reaction rates, mixing and surface-to-volume ratio are enhanced. Ongoing experimental and simulation work in plasma control and precision microdroplet generation, as well as a better understanding of droplet transport for the in-situ delivery of chemicals, will lead to opening new horizons for future plasma-aerosol applications [54].

The novelty of the presented work is the experimental study of the transport mechanism of highly vs. weakly soluble cold air plasma generated reactive species into the water: namely $\mathrm{H}_{2} \mathrm{O}_{2}$ vs. $\mathrm{O}_{3}$. The transport of these species is compared separately, into the bulk water through a simple water surface, and into aerosols generated by the ES. $\mathrm{H}_{2} \mathrm{O}_{2}$ and $\mathrm{O}_{3}$ concentrations dissolved into the water are measured, and their depletion from the gas phase due to this transport. Changing the water flow rate and the applied voltage on the ES needle electrode is considered a turning point between the lower to the larger surface area of the produced water droplets. ES creates accelerated charged droplets with different sizes, average speeds, and lifetimes inside the reactor filled with the studied gaseous species. These parameters are controlled with various gas flow rates of gaseous $\mathrm{H}_{2} \mathrm{O}_{2}$ and $\mathrm{O}_{3}$ during different treatment times when the water (bulk or aerosol) is exposed to these incident $\mathrm{H}_{2} \mathrm{O}_{2}$ and $\mathrm{O}_{3}$ species. Experimental results coupled with theoretical calculations are presented and the solvation saturation coefficients for $\mathrm{H}_{2} \mathrm{O}_{2}$ and $\mathrm{O}_{3}$ are analyzed separately. These analyses will lead to a deeper understanding of the reactive gaseous plasma species transport (e.g., $\mathrm{H}_{2} \mathrm{O}_{2}$ and $\mathrm{O}_{3}$ ) into the water for various surface-to-volume ratios, which underlines ozonation and many air plasma applications in water cleaning and disinfection, biomedicine, and agriculture.

\section{Theoretical Background}

In general, the solubility of the gaseous species in liquids, e.g., water, is described by Henry's law solubility coefficient $k_{H}$ :

$$
k_{H} \stackrel{\text { def }}{=} \frac{c_{i}}{p_{i}},
$$

where $c_{i}$ is the molar concentration of $i$-species in the aqueous phase and $p_{i}$ is the partial pressure of that species in the gas phase [55]. The $k_{H}$ is described as the proportionality factor of the amount of the dissolved gas in the aqueous phase to its partial pressure 
in the gas phase. In atmospheric chemistry, this coefficient is important to describe the distribution of trace species between the air and liquid droplets (aerosol). Henry's law coefficient can be also expressed as the dimensionless ratio between the aqueous-phase concentration $c_{i}$ of a species and its gas-phase concentration $c_{g}$ in Equation (2), where $R$ and $T$ are the gas constant and temperature, respectively.

$$
k_{H}^{c c} \stackrel{\text { def }}{=} c_{i} / c_{g}=k_{H} \times R T .
$$

Henry's law coefficient, however, does not describe the rate of the solvation process. It relates concentrations in the gas and the liquid phase in steady-state, with an equilibrated transfer (flux) of $i$-species from the gas into the liquid phase, and the backward transfer (flux) from the liquid into the gas phase. Out of equilibrium steady-state, which is typically the case in plasma-liquid interactions, these fluxes are not equal.

First, the flux of molecules from the gas into the liquid phase can be expressed:

$$
j_{i}^{+}=\frac{1}{4} n_{i} \overline{v_{i}}=\frac{\overline{v_{i}}}{4 k_{B} T} p_{i}=\beta p_{i} .
$$

Here, $n_{i}$ is the gas density of $i$-species, $v_{i}$ is their mean chaotic velocity, $p_{i}$ is their partial pressure, $k_{B}$ is the Boltzmann constant, and $T$ is the gas temperature.

Next, the flux from the liquid phase back to the gas phase can be assumed proportional to the molar concentration $c_{i}$ of $i$-species in the liquid phase:

$$
j_{i}^{-}=\alpha c_{i}
$$

In the steady-state, these two fluxes are equal, and it is possible to derive the constant $\alpha$ using Henry's law coefficient $k_{H}^{i}$ from Equation (1):

$$
c_{i}=\frac{\beta}{\alpha} p_{i}=k_{H}^{i} p_{i}
$$

Knowing the fluxes in both directions, the number of transferred $i$-th molecules $\Delta N_{i}$ in time $\Delta t$ into the liquid phase with surface area, $S$ can be expressed as:

$$
\Delta N_{i}=\left(\beta p_{i}-\alpha c_{i}\right) S \Delta t
$$

In combination with the expression $c_{i}=N_{i} /\left(N_{A} V\right)$, where $V$ is the volume of the liquid phase and $N_{A}$ is the Avogadro constant, an Equation describing the evolution of $c_{i}$ can be derived:

$$
\frac{\mathrm{d} c_{i}}{\mathrm{~d} t}=\frac{S \beta p_{i}}{N_{A} V}-\frac{S \beta}{N_{A} V k_{H}^{i}} c_{i} .
$$

Assuming an initial concentration of $i$-species in the liquid phase to be zero, $c_{i}(0)=0$, this expression for the aqueous concentration of $i$-species at time $t$ is obtained,

$$
c_{i}(t)=p_{i} k_{H}^{i}\left(1-\exp \left(\frac{-S \beta}{N_{A} V k_{H}^{i}} t\right)\right)
$$

It results from Equation (8) that with the increasing time, $c_{i}(t)$ converges towards the steady-state (saturated) concentration. In this simplified theory, it was assumed that the partial pressure $p_{i}$ does not change in time and that the concentration $c_{i}$ in the liquid phase is homogeneous. The real situation is more complicated, but this formula demonstrates the importance of surface-to-volume ratio $S / V$ and the role of $k_{H}$. It is in qualitative agreement with computational modeling results obtained by Kruzselnicki et al. [56,57], who observed that for species with lower $k_{H}$ (e.g., $\mathrm{O}_{3}$ ), microdroplets are saturated quickly while for high $k_{H}$ species (e.g., $\mathrm{H}_{2} \mathrm{O}_{2}$ ), solvation continue to increase their aqueous densities longer. 
They also showed that the larger $S / V$ ratio increases the rate of gas-phase solvation into the droplets if the droplet is under-saturated.

Hydrogen peroxide $\mathrm{H}_{2} \mathrm{O}_{2}$ and ozone $\mathrm{O}_{3}$ are examples of the plasma long-lived gaseous RONS. They have Henry's law solubility coefficient $k_{H} \approx 9 \times 10^{2}$ and $10^{-4} \mathrm{~mol} / \mathrm{m}^{3} \mathrm{~Pa}$, respectively. Henry's law solubility coefficient of $\mathrm{H}_{2} \mathrm{O}_{2}$ is almost 7 orders of magnitude larger than that of $\mathrm{O}_{3}$. This means that while $\mathrm{H}_{2} \mathrm{O}_{2}$ readily transfers into the water through the gas-liquid interface, $\mathrm{O}_{3}$ is hardly dissolved into water based on its very low Henry's law coefficient. For this reason, the assumption of constant partial pressure $p_{i}$ is generally valid only for low $k_{H}$ species (e.g., $\mathrm{O}_{3}$ ), as shown by Verlackt et al. [58], who investigated $\mathrm{H}_{2} \mathrm{O}_{2}$ and $\mathrm{O}_{3}$ as examples of highly and lowly soluble cold plasma species in a 2D axisymmetric fluid model. The density of $\mathrm{H}_{2} \mathrm{O}_{2}$ species shows a sudden drop at the gas-liquid interface due to the fast transfer into the liquid, where its density is significantly higher compared to the gas phase. On the other hand, the density of $\mathrm{O}_{3}$ species remains constant above the gas-liquid interface for $1 \mathrm{~min}$ of plasma treatment, where its density is much higher in the gas phase compared to the liquid phase.

For high $k_{H}$ species (e.g., $\mathrm{H}_{2} \mathrm{O}_{2}$ ), the gas density of species is not significantly depleted and $p_{i}$ can be considered constant only if the total volume of water is small and thus small amount of the gas phase species can be dissolved. Kruszelnicki et al. observed that for aerosol solvation, the $\mathrm{H}_{2} \mathrm{O}_{2}$ depletion is negligible only for microdroplets with a diameter below $\sim 30 \mu \mathrm{m}$ [57]. For bigger microdroplets with a larger volume, the surrounding $\mathrm{H}_{2} \mathrm{O}_{2}$ of these microdroplets was already depleted.

\section{Materials and Methods}

The transport of gaseous $\mathrm{H}_{2} \mathrm{O}_{2}$ and $\mathrm{O}_{3}$ generated by external sources into water is investigated in two types of reactors: bulk water and electrosprayed (ES) aerosols. The concentration of dissolved $\mathrm{H}_{2} \mathrm{O}_{2}$ and $\mathrm{O}_{3}$ in the water and their loss in the gas phase was measured. The optical imaging technique was employed to analyze the size, density, and surface area of the electrosprayed water microdroplets during the transport of $\mathrm{H}_{2} \mathrm{O}_{2}$ and $\mathrm{O}_{3}$ from air into water.

\subsection{Generation and Analysis of $\mathrm{H}_{2} \mathrm{O}_{2}$ and $\mathrm{O}_{3}$ in the Gas Phase}

Because of relatively low concentrations of $\mathrm{H}_{2} \mathrm{O}_{2}$ and $\mathrm{O}_{3}$ generated by the positive corona discharge that are typically used in biomedical applications [21,31,32,42], two different external gas sources of higher concentrations of $\mathrm{H}_{2} \mathrm{O}_{2}$ and $\mathrm{O}_{3}$ were used here. This enabled us to study the species transport into the water at higher gaseous concentrations. $\mathrm{H}_{2} \mathrm{O}_{2}$ and $\mathrm{O}_{3}$ gases were studied individually, where each one was mixed separately with an airflow to form a gas mixture with a specific dilution ratio, flow rate, and gas concentration. This gas mixture was pumped into two different reactors (ES and bulk) through PTFE tubes with an inner diameter of $4 \mathrm{~mm}$ and then measured by two individual electrochemical gas sensors of $\mathrm{H}_{2} \mathrm{O}_{2}$ and $\mathrm{O}_{3}$, type MEMBRAPOR. The gas sensors were connected to the reactor by PTFE and silicon tubes with the same inner diameter. Each gas sensor was attached to its transmitter board connected with an Arduino circuit, where the functional code is uploaded and displayed on LCD showing the gas concentrations in ppm.

The external source for $\mathrm{H}_{2} \mathrm{O}_{2}$ is a bubbler glass tube containing commercially available $30 \%(w / w) \mathrm{H}_{2} \mathrm{O}_{2}$ solution in water with a corresponding molar concentration of $9.8 \mathrm{M}$. It is bubbled at room temperature using a variable airflow to produce $\mathrm{H}_{2} \mathrm{O}_{2}$ vapor with a high relative humidity $>90 \%$. This $\mathrm{H}_{2} \mathrm{O}_{2}$ vapor is mixed by a 1:1 ratio with dry air from an air pump to avoid the condensing of the water vapor in the $\mathrm{H}_{2} \mathrm{O}_{2}$ gas sensor and to keep the sensor's recommended relative humidity range of $15-90 \%$. The $\mathrm{H}_{2} \mathrm{O}_{2}$ gas sensor type $\mathrm{H}_{2} \mathrm{O}_{2} / \mathrm{CB}-500$ has a nominal range of $0-500 \mathrm{ppm}$ with a resolution $<1 \mathrm{ppm}$ and maximum overload of $1000 \mathrm{ppm}$. The $\mathrm{H}_{2} \mathrm{O}_{2}$ experiment was run at a concentration value of $\sim 110 \mathrm{ppm}$ of $\mathrm{H}_{2} \mathrm{O}_{2}$. 
The $\mathrm{O}_{3}$ generator type EASELEC was used as an external source of $\mathrm{O}_{3}$ with an $\mathrm{O}_{3}$ output of $300 \mathrm{mg} / \mathrm{h}$ and a flow rate $2-3 \mathrm{~L} / \mathrm{min}$, which is mixed by 2:1 ratio with an airflow produced by an air pump to reach a stable concentration of $\sim 450 \mathrm{ppm}$ of $\mathrm{O}_{3}$ before starting the $\mathrm{O}_{3}$ experiment. Since the $\mathrm{O}_{3}$ generator has a constant output flow rate, a by-pass valve in one of its two output terminals was used to avoid limiting its designed gas flow rate and allow a lower concentration of $\mathrm{O}_{3}$ than its default output. The $\mathrm{O}_{3}$ gas sensor type $\mathrm{O}_{3} / \mathrm{C}-1000$ has a nominal range of $0-1000 \mathrm{ppm}$ with a resolution of $0.3 \mathrm{ppm}$ and maximum overload of 2000 ppm.

The air-flow rate with $\mathrm{H}_{2} \mathrm{O}_{2}$ vapor or $\mathrm{O}_{3}$ gas was controlled using flow meters AALBORG. During each experiment of $\mathrm{H}_{2} \mathrm{O}_{2}$ or $\mathrm{O}_{3}$, the gas sensors are supposed to record a decrease in the $\mathrm{H}_{2} \mathrm{O}_{2}$ or $\mathrm{O}_{3}$ concentration of the gas mixture inside the reactor. This concentration loss in the gas phase represents how much of the $\mathrm{H}_{2} \mathrm{O}_{2}$ or $\mathrm{O}_{3}$ species were transported/dissolved into the water (bulk or aerosols).

\subsection{Transport of Gaseous $\mathrm{H}_{2} \mathrm{O}_{2}$ and $\mathrm{O}_{3}$ into the Bulk Water}

The experimental setup shown in Figure 1, consists of the air pump, external sources of $\mathrm{H}_{2} \mathrm{O}_{2}$ vapor and $\mathrm{O}_{3}$ gases, and gas sensors as described in the previous section.

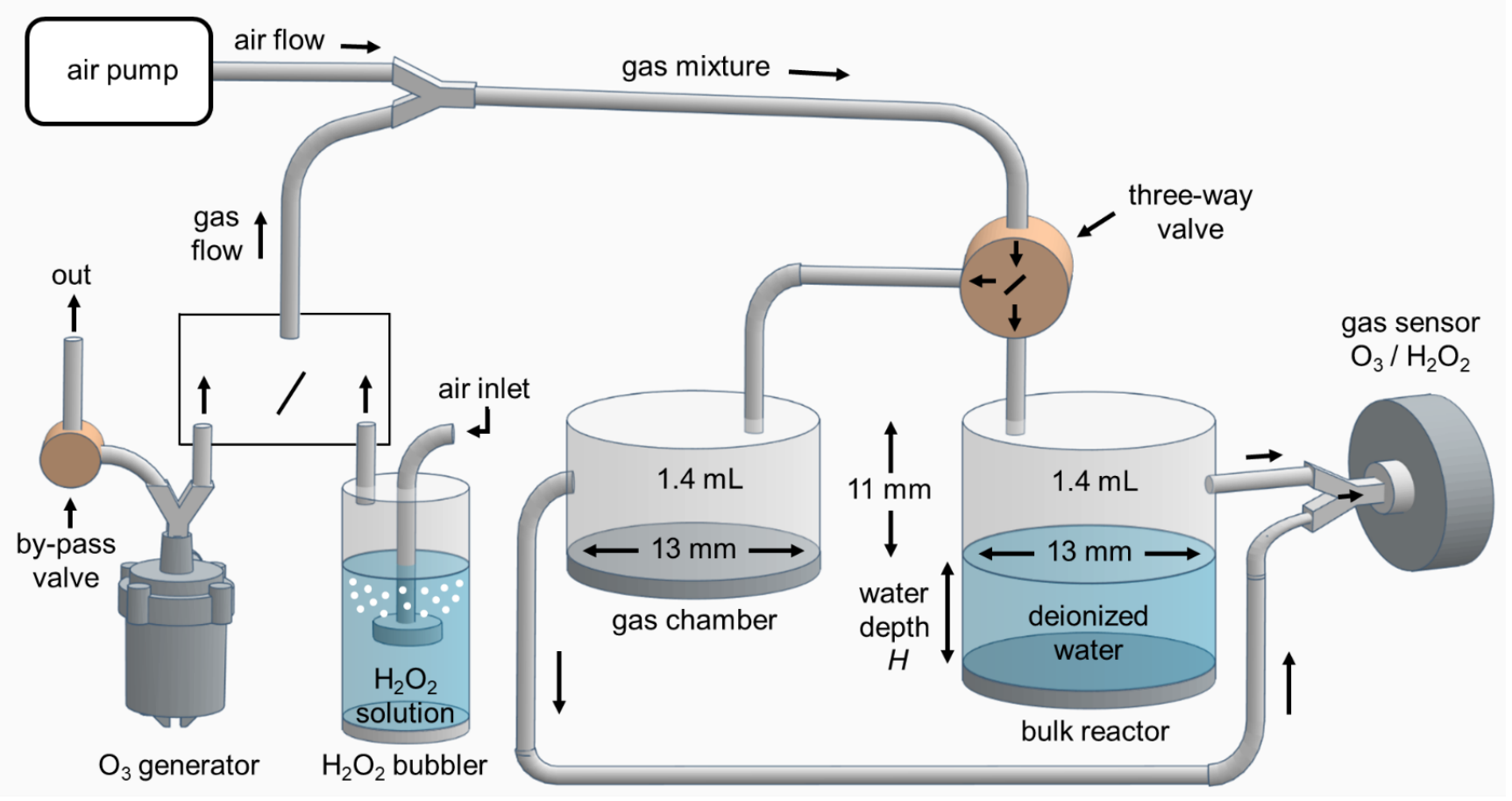

Figure 1. Schematic of the experimental setup for investigation $\mathrm{H}_{2} \mathrm{O}_{2}$ and $\mathrm{O}_{3}$ transport into bulk water.

The bulk water reactor and the gas chamber have the same cylindrical geometry and dimensions (diameter, height, and volume of the gaseous space $13 \mathrm{~mm}, 11 \mathrm{~mm}$, and $1.4 \mathrm{~mL}$, respectively) were used in parallel. There is a piston at the bottom of the bulk reactor to keep the height and volume of the gaseous space constant for different water volumes. The filled bulk of deionized water (with conductivity $<3 \mu \mathrm{S} / \mathrm{cm}$ ) at the bottom of the reactor has a fixed surface area exposed to $\mathrm{H}_{2} \mathrm{O}_{2}$ or $\mathrm{O}_{3}$ gaseous species. The volume of the bulk water is determined by its depth $H$.

The gas mixture of $\mathrm{H}_{2} \mathrm{O}_{2}$ diluted vapor or $\mathrm{O}_{3}$ diluted gas is first pumped through a three-way valve type BUERKLE PP/PE (Bad Bellingen, Germany) into the gas chamber with no water and then into the gas sensor. When reaching the stable starting point of the gas concentrations 110 or 450 ppm for the $\mathrm{H}_{2} \mathrm{O}_{2}$ vapor or $\mathrm{O}_{3}$ gas, respectively, the gas mixture is transferred into the bulk reactor filled with the specific water volume. At that moment, the treatment time is started, and the gas sensor is connected to the bulk reactor. 
The treatment time means the exposure time of this bulk water (with a fixed surface area and different volumes) to the incoming gas mixture. There was slight turbulence of the surface of the water bulk during the flow of the gas mixture at the highest flow rates used (2 L/min).

\subsection{Analysis of the Sizes of Water Microdroplets using Fast/HS Camera Imaging and Transport of Gaseous $\mathrm{H}_{2} \mathrm{O}_{2}$ and $\mathrm{O}_{3}$ into the Water Aerosols}

The diameter and density of the water aerosol (large droplets + electrosprayed microdroplets) were measured by high-speed visualization to investigate the transport of the gaseous species into the water. Figure 2 shows the schematic diagram of the ES experimental setup. It consists of a positive dc High Voltage (HV) power supply type Spellman's Bertan model 210-30R of $135 \mathrm{~W}$ and a syringe pump type NE-300 which delivers the deionized water (with conductivity $<3 \mu \mathrm{S} / \mathrm{cm}$ ) continuously through a silicon tube with an inner diameter of $2 \mathrm{~mm}$ and controlled water flow rates (100-1000) $\mu \mathrm{L} / \mathrm{min}$ into a blunt hollow needle electrode (anode) nozzle with the outer and inner diameters 0.7 and $0.5 \mathrm{~mm}$, respectively. The needle electrode is placed opposite to a rounded wire of $1.5 \mathrm{~mm}$ diameter as a grounded electrode (cathode). The two electrodes are in point-to-plane geometry, both are stainless-steel with the shortest gap distance of $16 \mathrm{~mm}$. HV from the power supply is applied through a ballast resistor $13.5 \mathrm{M} \Omega$ on the needle electrode. This $\mathrm{HV}$ is measured using a dc HV probe type AGILENT N2771A (Santa Clara, CA, USA) and then processed by a digital oscilloscope type TEKTRONIX TDS 1012 (Beaverton, OR, USA).

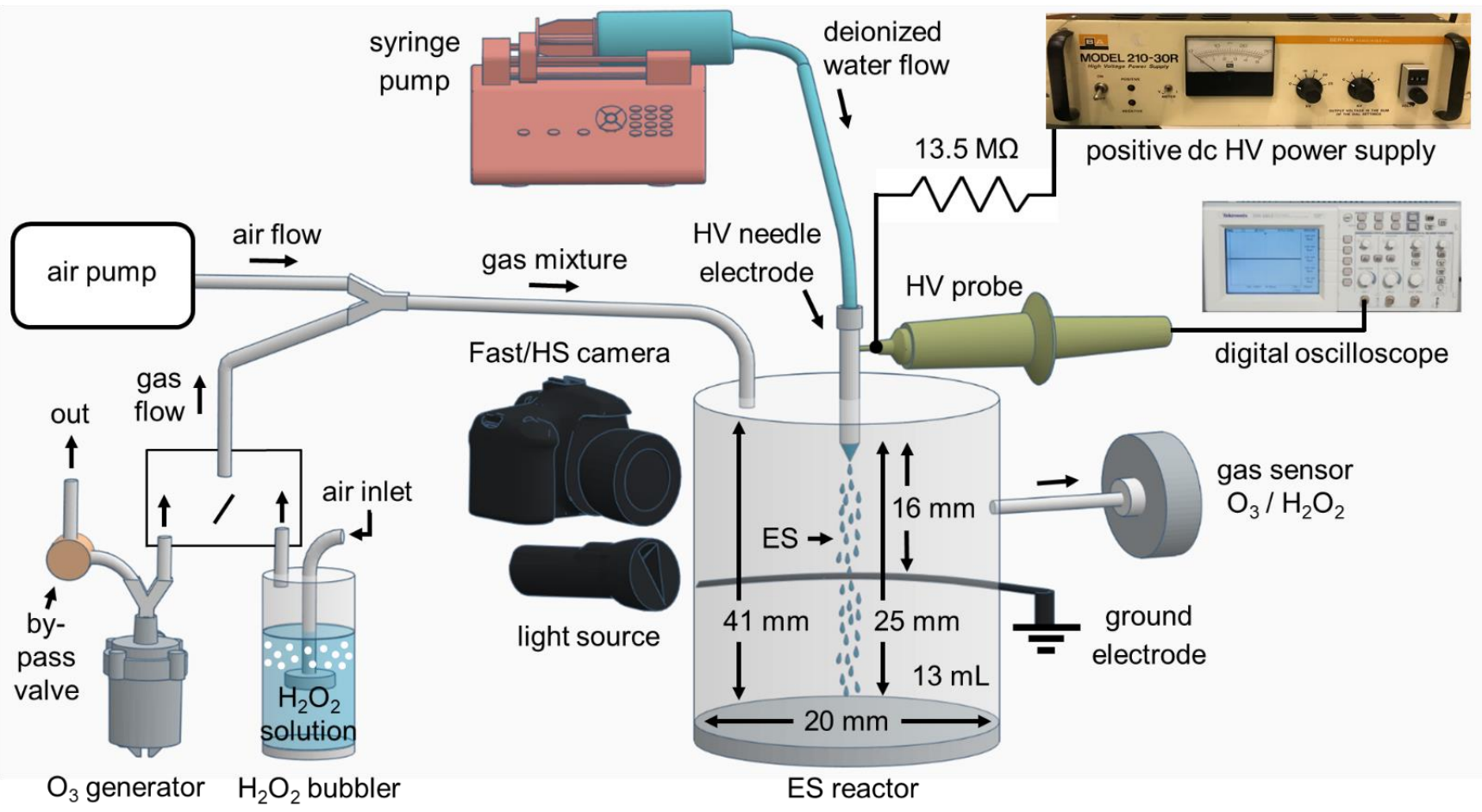

Figure 2. Schematic of the experimental setup for the Fast/high speed (HS) camera imaging technique and investigation $\mathrm{H}_{2} \mathrm{O}_{2}$ and $\mathrm{O}_{3}$ transport into water electrospray (ES).

Two types of cameras placed in front of the water aerosols were used to visualize the electrosprayed aerosol and measure the size of the water droplets. A digital Fast camera type CASIO EXILIM was used mainly for the slower and larger size water droplets, with typical record parameters $60 \mathrm{fps}$ (frame per second) and shutter speed 1/40,000 s (exposure time $25 \mu \mathrm{s}$ ). It provided photographs of the size $562 \times 623$ pixels and resolution $29.2 \mu \mathrm{m} /$ pixel. Additionally, high speed (HS) camera Photron FASTCAM SA-Z type 2100KC-32GB (Fujimi, Tokyo, Japan) was used mainly for the faster and lower size of the water 
microdroplets produced during the ES process, with typical record parameters 25,000 fps and shutter speed $1 / 50,000 \mathrm{~s}$ and 1/133,333 s (exposure time 20-7.5 $\mu \mathrm{s}$ ) which provided photographs of the size $840 \times 1024$ pixels and resolution $21.875 \mu \mathrm{m} /$ pixel.

To improve the spatial resolution of the camera at short exposure times and high shutter speed, sufficient light illumination was needed. The droplets were illuminated with two strong light sources, white LED type LEDLENSER P7R (Solingen, Germany) placed in front of the Fast camera with the droplets in between, and type DEDOLIGHT daylight 400D (Munchen, Germany) placed beside the HS camera directed to the microdroplets. The Fast/HS camera records photographs of the electrosprayed water microdroplets, which were processed and analyzed by the software Microsoft Office Picture Manager and GIMP (version 2.10.22).

To allow a very efficient mass transfer of the studied species $\left(\mathrm{H}_{2} \mathrm{O}_{2}\right.$ and $\left.\mathrm{O}_{3}\right)$ into water aerosols and to enable the gas analyses and measurements, the HV needle and the ground wire electrodes were enclosed inside a transparent plastic reactor in which the water aerosols (large droplets + ES microdroplets) are produced and collected. It has a cylindrical geometry with the dimensions of diameter, height, and volume of gaseous space: $20 \mathrm{~mm}, 41 \mathrm{~mm}$, and $13 \mathrm{~mL}$, respectively. The transport process of $\mathrm{H}_{2} \mathrm{O}_{2}$ and $\mathrm{O}_{3}$ gaseous species into water aerosols occurs in this gaseous space along with a $25 \mathrm{~mm}$ flight distance of the water microdroplets from the needle electrode to the bottom of the reactor. The lifetime of these water microdroplets is the time before they reach the bottom of the ES reactor. There is an adjustable piston at the bottom of the reactor to keep the constant volume of the gaseous space and the flight distance when working with different water flow rates and treatment times.

Before starting the water flow and the applied $\mathrm{HV}$ on the needle electrode, the gas mixture of $\mathrm{H}_{2} \mathrm{O}_{2}$ vapor or $\mathrm{O}_{3}$ gas diluted with air was pumped into the ES reactor, and the gas sensors were employed for measuring their gas concentration. The $\mathrm{H}_{2} \mathrm{O}_{2}$ or $\mathrm{O}_{3}$ experiment started when the gas mixture concentration of $\mathrm{H}_{2} \mathrm{O}_{2}$ vapor or $\mathrm{O}_{3}$ gas reached 110 or $450 \mathrm{ppm}$, respectively. Then the water flow at the specific applied voltage on the needle electrode was started, for a given treatment time. The treatment time is the exposure time of the water aerosols to the gas mixture from the start until the end of the water flow.

\subsection{Analysis of $\mathrm{H}_{2} \mathrm{O}_{2}$ and $\mathrm{O}_{3}$ in the Aqueous Phase Using $U V$-Vis Spectroscopy}

The aqueous phase analysis is related to the amount of the gas concentrations of $\mathrm{H}_{2} \mathrm{O}_{2}$ and $\mathrm{O}_{3}$ in the gas phase, which are dissolved/transported into the water aerosols and bulk. UV-vis spectroscopy colorimetric methods were used for the chemical analysis of $\mathrm{H}_{2} \mathrm{O}_{2}$ and $\mathrm{O}_{3}$ in the aqueous phase. The collected water samples with added chemical reagents were analyzed by a UV/VIS absorption spectrophotometer UV-1800 Shimadzu.

For $\mathrm{H}_{2} \mathrm{O}_{2}, \mathrm{TiOSO}_{4}$ (titanium oxysulfate) reagent was used. $\mathrm{H}_{2} \mathrm{O}_{2}$ reacts with the titanium (IV) ions under acidic conditions which produced a yellow-colored product of pertitanic acid $\mathrm{H}_{2} \mathrm{TiO}_{4}$ with the absorption maximum at $407 \mathrm{~nm}$ [59]. The concentration of $\mathrm{H}_{2} \mathrm{O}_{2}$ is proportional to the absorbance according to Lambert-Beer's law (molar extinction coefficient $\varepsilon=6.89 \times 10^{2} \mathrm{~L} / \mathrm{mol} . \mathrm{cm}$ ).

For $\mathrm{O}_{3}$, a simple quantitative colorimetric standardized detection method was used for the dissolved $\mathrm{O}_{3}$ in water using the indigo blue reagent II for higher concentrations of $\mathrm{O}_{3}(0.05-0.5 \mathrm{mg} / \mathrm{L})[32,60] . \mathrm{O}_{3}$ decolorizes the indigo potassium trisulfonate dye rapidly in acidic conditions and the colorless product isatin is formed by the bleaching process. The decrease of the absorbance at $600 \mathrm{~nm}\left(\varepsilon=2.38 \times 10^{4} \mathrm{~L} / \mathrm{mol} . \mathrm{cm}\right)$ is linearly proportional to the increase of $\mathrm{O}_{3}$ concentration. Although this analytical method has limitations in air plasma-treated solutions due to cross-correlations with other plasma generated RONS, especially peroxynitrites [61], it can be safely used in this experiment with air containing $\mathrm{O}_{3}$ only. 


\section{Results and Discussion}

The aim of the electrospray (ES) formation is to increase the size of the gas/plasmaliquid interface area compared to the bulk liquid experiments. In this section, the results from the bulk water solvation of $\mathrm{O}_{3}$ and $\mathrm{H}_{2} \mathrm{O}_{2}$ (Section 4.1) will be first presented and discussed, then the results of the visualization of microdroplets (Section 4.2). These experiments enabled us to estimate the surface area of electrosprayed microdroplets, which is then compared to the surface area in experiments with the bulk water. Measured molar amounts of dissolved $\mathrm{O}_{3}$ and $\mathrm{H}_{2} \mathrm{O}_{2}$ in the bulk experiment will be then compared to the results from ES solvation experiments (Section 4.3). Finally, a simple theoretical-analytical model will be presented to explain some of the observed phenomena (Section 4.4).

\subsection{Solvation of $\mathrm{O}_{3}$ and $\mathrm{H}_{2} \mathrm{O}_{2}$ in Bulk Water}

Figure 3 shows the amount of dissolved $\mathrm{O}_{3}$ and $\mathrm{H}_{2} \mathrm{O}_{2}$ into bulk water at various water volumes and treatment (interaction) times. Both $\mathrm{O}_{3}$ and $\mathrm{H}_{2} \mathrm{O}_{2}$ solvation depends almost linearly on the treatment time. It is interesting to compare the dissolved molar amounts of $\mathrm{O}_{3}$ and $\mathrm{H}_{2} \mathrm{O}_{2}$ : while $\mathrm{O}_{3}$ dissolves at the maximum of $0.9 \mathrm{nmol}$ (gas flow rate $0.8 \mathrm{~L} / \mathrm{min}$, interaction time $4 \mathrm{~min}$ in Figure 3a), $\mathrm{H}_{2} \mathrm{O}_{2}$ dissolves up to $10 \mu \mathrm{mol}$ in Figure $3 \mathrm{c}$ at similar conditions. This agrees with a much higher Henry's law coefficient $k_{H}$ of $\mathrm{H}_{2} \mathrm{O}_{2}$ compared to $\mathrm{O}_{3}$; however, the measured difference is just four, not seven orders of magnitude as one would expect based on the difference of $k_{H}$.

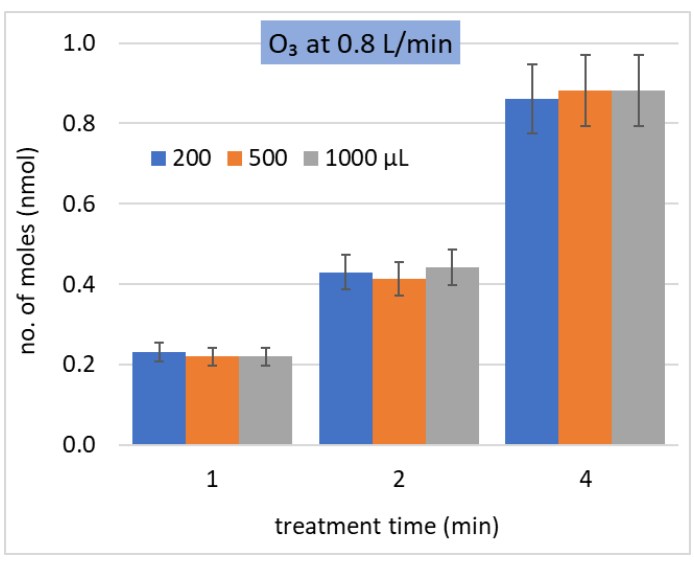

(a)

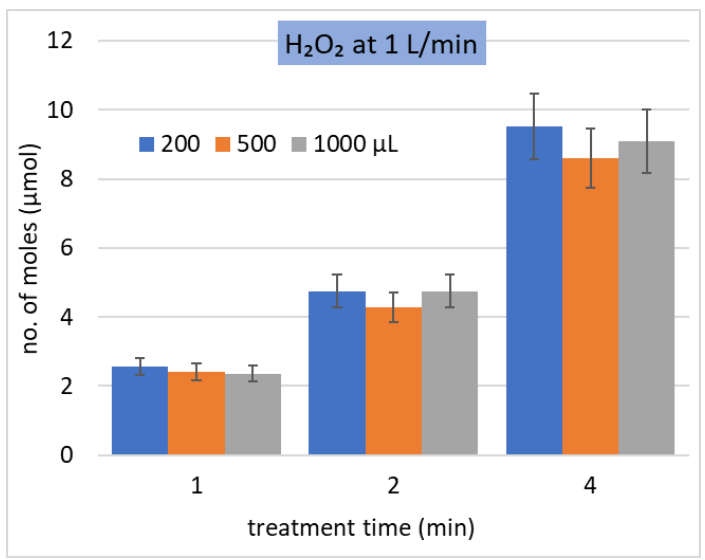

(c)

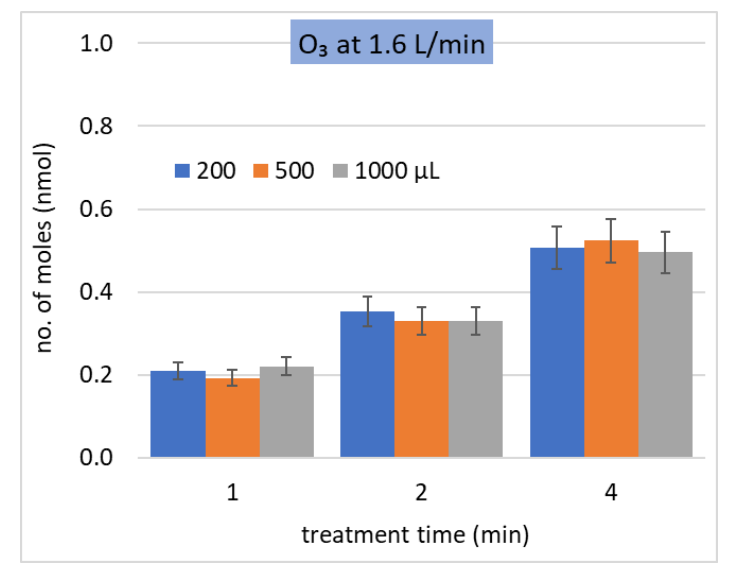

(b)

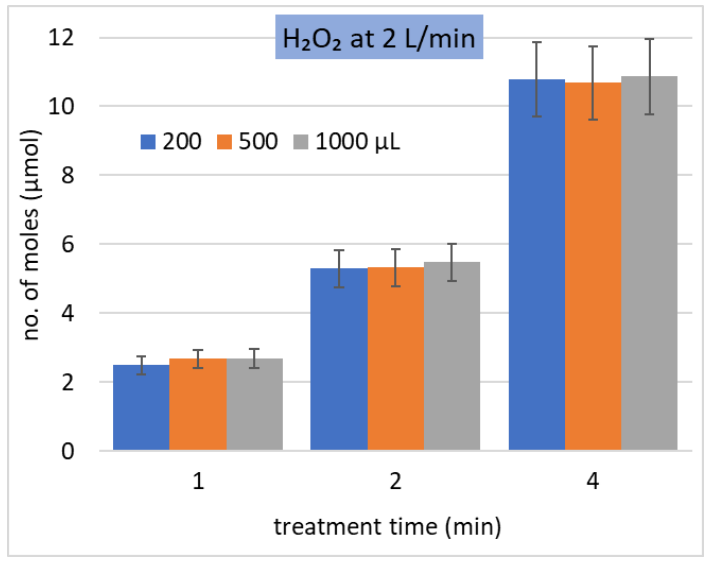

(d)

Figure 3. Solvation of $(\mathbf{a}, \mathbf{b}) \mathrm{O}_{3}$ and $(\mathbf{c}, \mathbf{d}) \mathrm{H}_{2} \mathrm{O}_{2}$ at different gas flow rates ( $\left.\mathrm{L} / \mathrm{min}\right)$ and water volumes $(\mu \mathrm{L})$ during different treatment times ( $\mathrm{min}$ ) in bulk water. Total molar number of dissolved molecules as a function of treatment time, different water volumes, at constant gas-liquid interface area. 
The surface area of the bulk water was kept constant $\left(133 \mathrm{~mm}^{2}\right)$ for all tested volumes. No influence of the water volume (i.e., the height of the water column in the bulk reactor) was detected for the same treatment time. This also shows that the total gas-water interface surface area is the key parameter determining the solvation.

At the higher gas flow rate, the residence time of the gas inside the reactor; thus, also gas-liquid interaction time, were shorter and the amount of dissolved $\mathrm{O}_{3}$ decreased, despite the higher amount of $\mathrm{O}_{3}$ delivered into the reactor per unit time (Figure 3a,b). On the other hand, for $\mathrm{H}_{2} \mathrm{O}_{2}$, the higher gas flow rate resulted in slightly higher solvation, due to the higher amount of $\mathrm{H}_{2} \mathrm{O}_{2}$ delivered into the reactor per unit time (Figure $3 \mathrm{c}, \mathrm{d}$ ), despite the shorter gas-liquid interaction time.

\subsection{Visualization of Electrosprayed Water Droplets}

When a high voltage $\left(V_{a}\right)$ is applied on the needle nozzle through which the water is delivered to the reactor with a water flow rate $\left(Q_{w}\right)$, the ES starts at $7.5 \mathrm{kV}$ (at the lower $Q_{w}$ ) while the dc corona discharge plasma onset occurs at $9 \mathrm{kV}$. Figure 4 shows an example of electrosprayed microdroplets obtained by HS camera imaging. From a large set of HS camera images, the size distribution of the ES water microdroplets (Figure 5) is estimated. In addition to $V_{a}$ (Figure $5 \mathrm{a}$ ), $Q_{w}$ also influences this size distribution (Figure $5 \mathrm{~b}$ ). However, the differences do not seem to be very significant. In all histograms, the largest number of droplets have a diameter around $50 \mu \mathrm{m}$ and there are only a few droplets with a diameter above $\sim 150 \mu \mathrm{m}$. The abundance of these "big" droplets slightly decreases with increasing $V_{a}$ and decreasing $Q_{w}$.

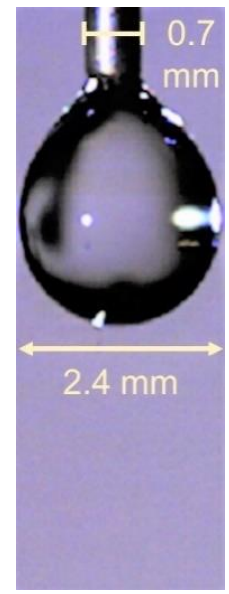

(a)

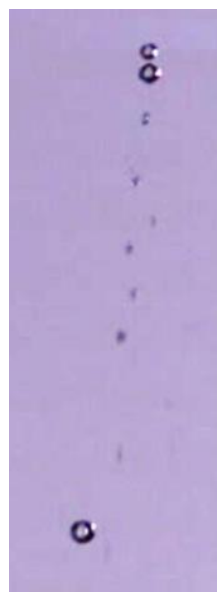

(b)

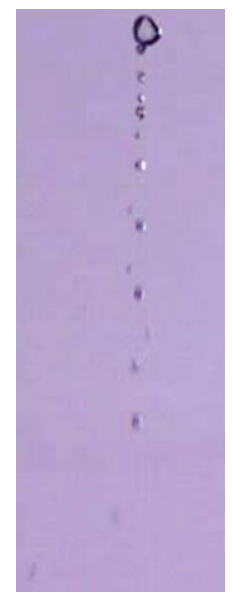

(c)

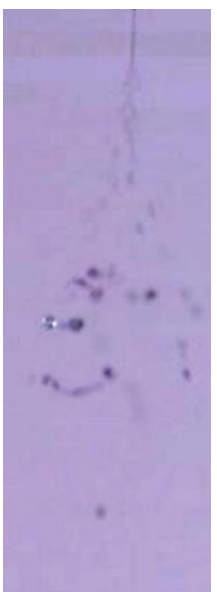

(d)

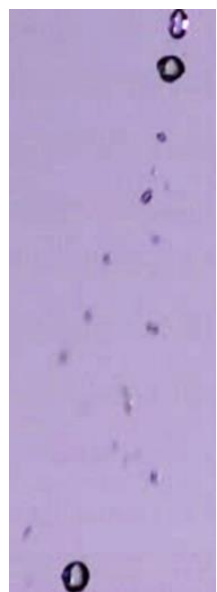

(e)

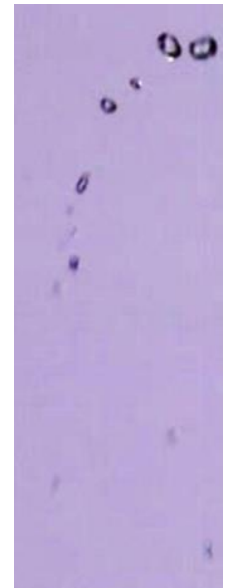

(f)

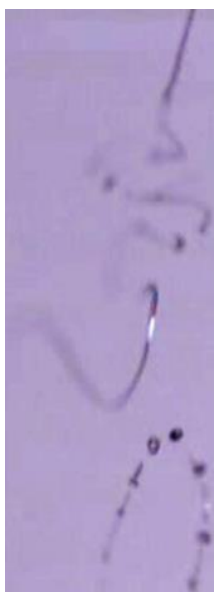

(g)

Figure 4. Examples of water droplets photographs by HS camera for different $V_{a}(\mathrm{kV})$ and $Q_{w}(\mu \mathrm{L} / \mathrm{min}):(\mathbf{a}) 0 \mathrm{kV} ;(\mathbf{b}) 9 \mathrm{kV}$, $300 \mu \mathrm{L} / \mathrm{min}$; (c) $11 \mathrm{kV}, 300 \mu \mathrm{L} / \mathrm{min}$; (d) $13 \mathrm{kV}, 300 \mu \mathrm{L} / \mathrm{min}$; (e) $9 \mathrm{kV}, 500 \mu \mathrm{L} / \mathrm{min}$; (f) $11 \mathrm{kV}, 500 \mu \mathrm{L} / \mathrm{min}$; (g) $13 \mathrm{kV}$, $500 \mu \mathrm{L} / \mathrm{min}$.

Next, the total surface area of the water ES droplets integrated for $1 \mathrm{~min}$ was estimated from the droplet size distributions. Figure 6 shows this total surface area for different $Q_{w}$ as a function of $V_{a}$ and it is compared with the surface area of the bulk water and water droplets (with diameter 1.5-2 $\mathrm{mm}$ ) at $5 \mathrm{kV}$. There is a significant increase with increasing $V_{a}$ and $Q_{w}$. At $13 \mathrm{kV}$ and $500 \mu \mathrm{L} / \mathrm{min}$ for $1 \mathrm{~min}$, the produced total surface area is almost 190 times larger than the area in the bulk liquid experiment. 


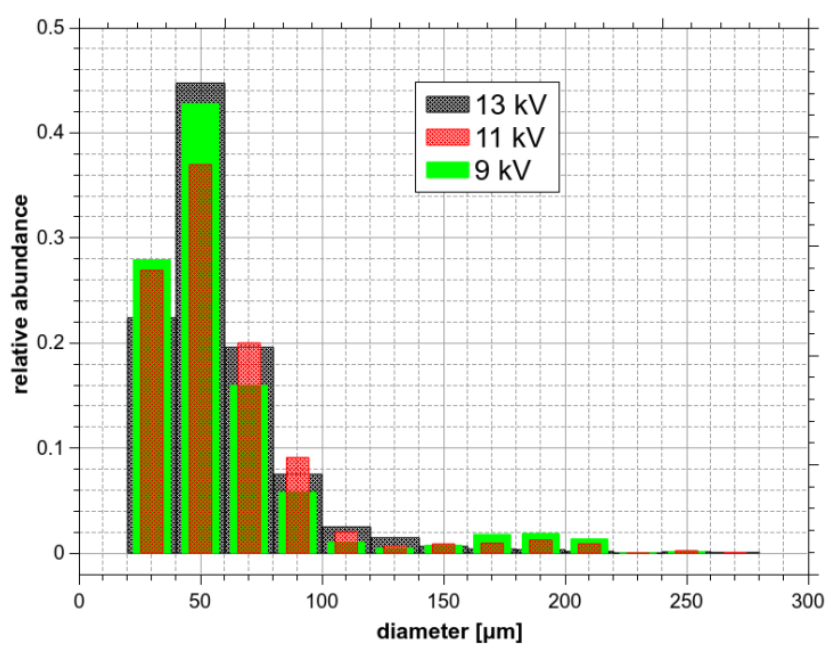

(a)

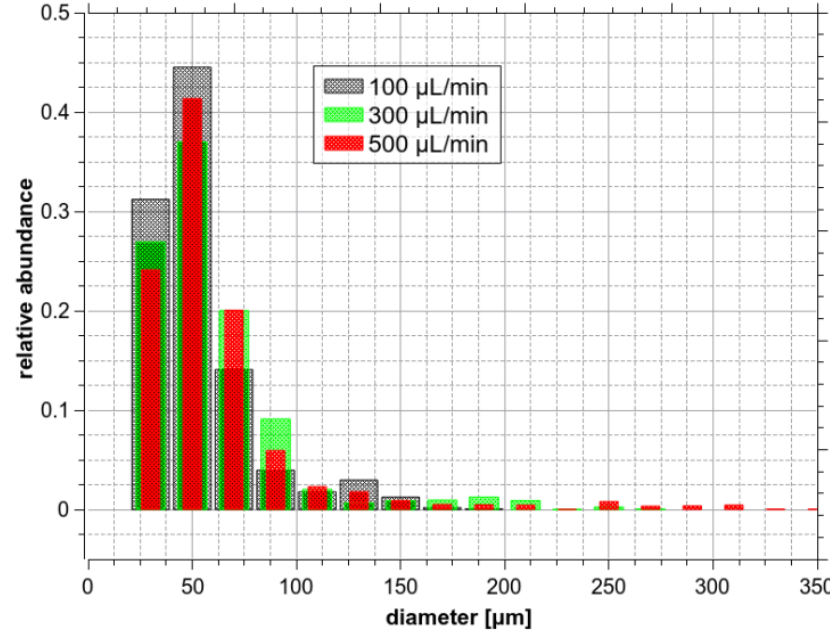

(b)

Figure 5. The relative abundance of water microdroplets produced by ES as a function of microdroplets diameter at different $V_{a}(\mathrm{kV})$ and $Q_{w}(\mu \mathrm{L} / \mathrm{min})$ : (a) 9, 11, $13 \mathrm{kV}$, and $300 \mu \mathrm{L} / \mathrm{min}$; (b) $11 \mathrm{kV}$ and 100, 300, $500 \mu \mathrm{L} / \mathrm{min}$. Microdroplets with a diameter under $20 \mu \mathrm{m}$ are below the detection limit of the used camera imaging technique.

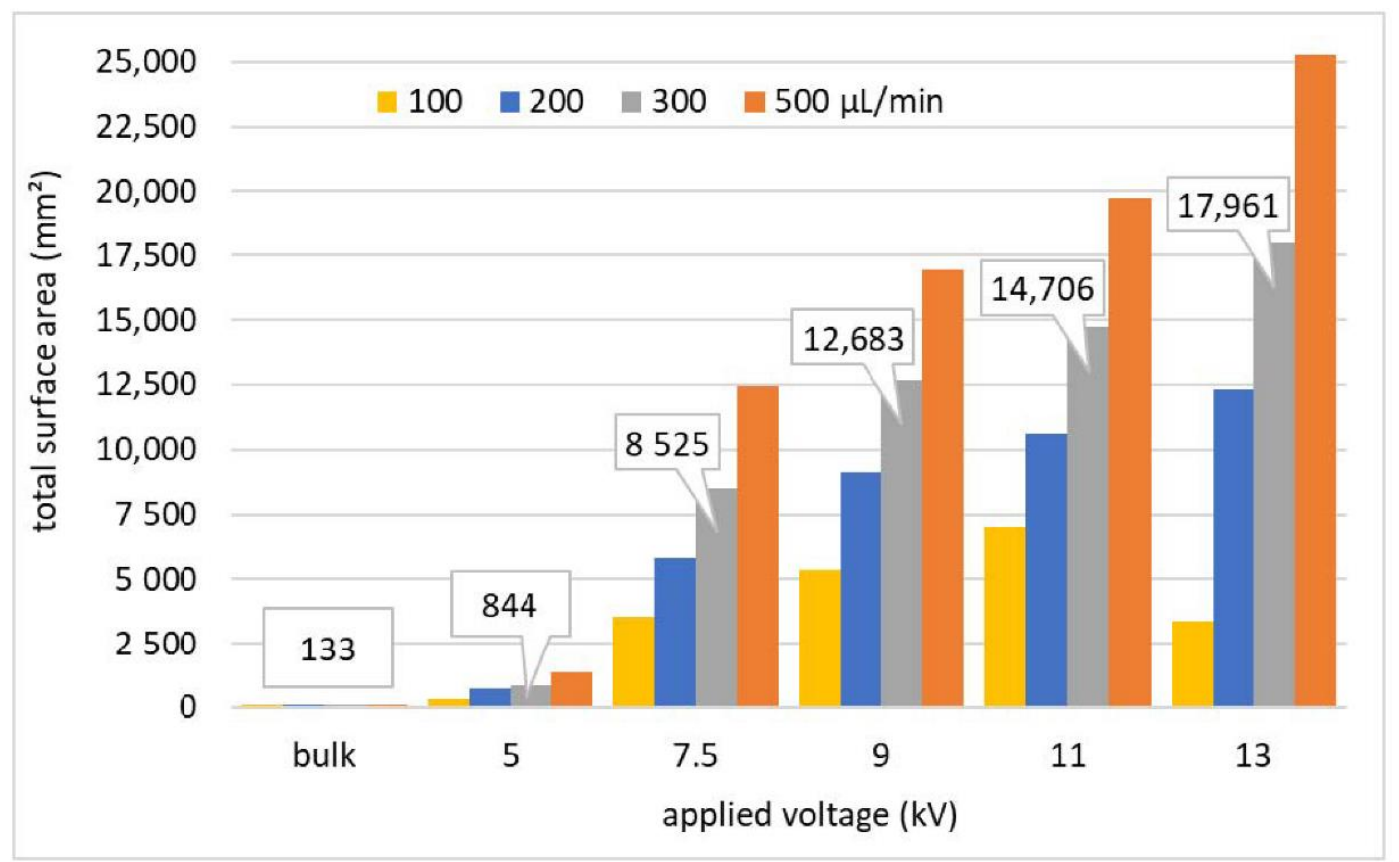

Figure 6. The total surface area of water droplets and microdroplets formed by ES during 1 min for different $Q_{w}(\mu \mathrm{L} / \mathrm{min}$ ) as a function of $V_{a}(\mathrm{kV})$, compared to the bulk water experiment.

\subsection{Solvation of $\mathrm{O}_{3}$ and $\mathrm{H}_{2} \mathrm{O}_{2}$ in Electrosprayed Water Droplets}

In coherence with the bulk water experiment, the amount of dissolved $\mathrm{O}_{3}$ and $\mathrm{H}_{2} \mathrm{O}_{2}$ into ES droplets increases with the treatment time, as shown in Figure $7 \mathrm{a}, \mathrm{b}$ for $\mathrm{O}_{3}$, and Figure $8 \mathrm{~b}, \mathrm{c}$ for $\mathrm{H}_{2} \mathrm{O}_{2}$. However, this solvation rate is slower than linearly proportional with time, as observed in the bulk water experiment. The dissolved $\mathrm{O}_{3}$ and $\mathrm{H}_{2} \mathrm{O}_{2}$ also increase with increasing $V_{a}$ and $Q_{w}$ (Figure 7c,d for $\mathrm{O}_{3}$ and Figure $8 \mathrm{a}, \mathrm{b}$ for $\mathrm{H}_{2} \mathrm{O}_{2}$ ), although the effect of increasing $Q_{w}$ is not so significant in some cases. 


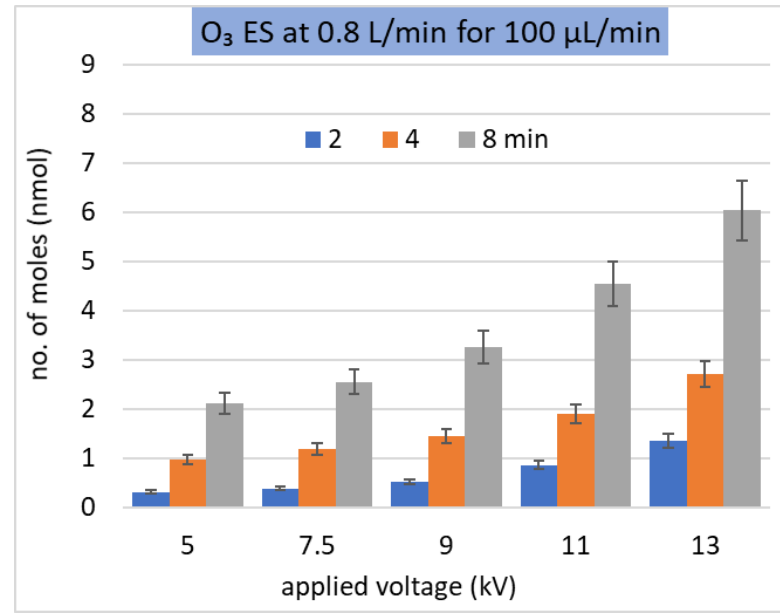

(a)

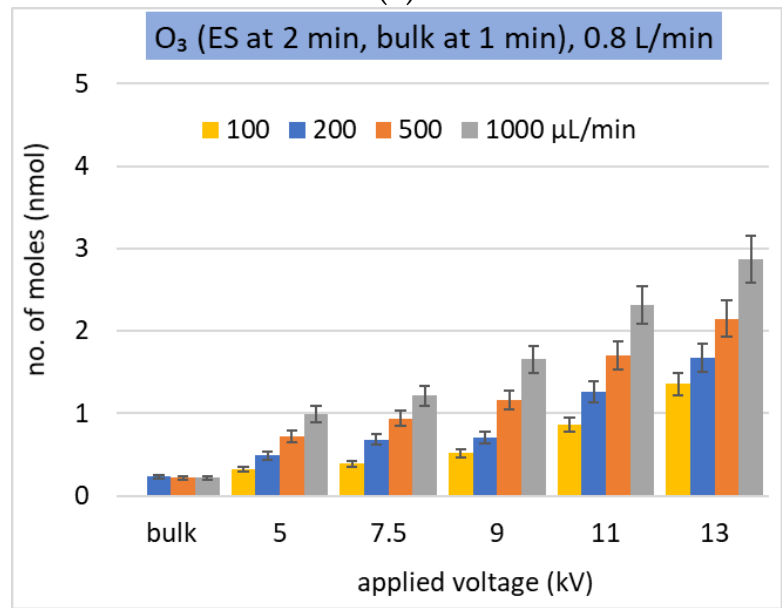

(c)

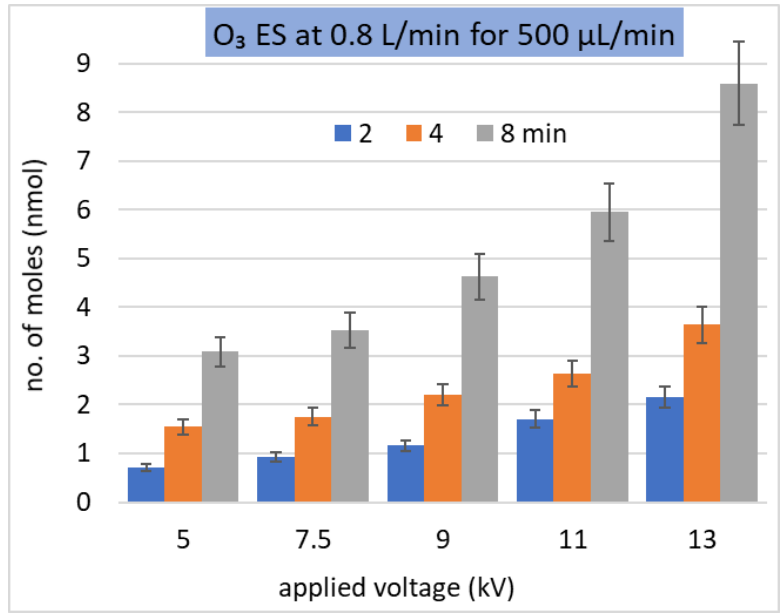

(b)

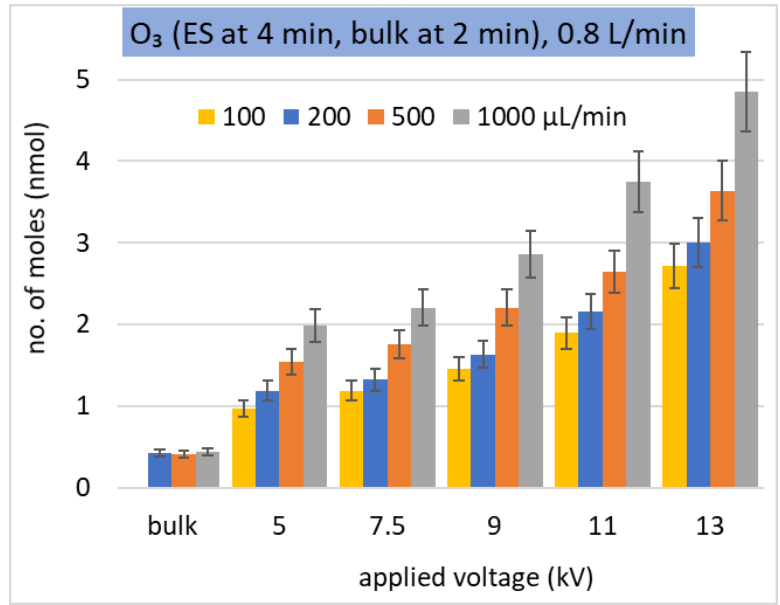

(d)

Figure 7. Solvation of $\mathrm{O}_{3}$ as a molar number of dissolved molecules in ES at a constant gas flow rate (L/min). (a,b) two values of constant $Q_{w}(\mu \mathrm{L} / \mathrm{min})$ and different treatment times (min); (c,d) different $Q_{w}(\mu \mathrm{L} / \mathrm{min})$ during different treatment times (min) in ES and bulk water.

Similar to the bulk experiment, the amount of dissolved $\mathrm{H}_{2} \mathrm{O}_{2}$ is much higher than that of $\mathrm{O}_{3}$, but not by seven orders of magnitude, as could be expected from the ratio of their Henry's law coefficients. In order to understand it, the number of molecules in the gas available for solvation in the liquid must be considered, and the number needed to achieve the saturated concentration $c_{i}^{\text {satur. }}$ (index $i$ denotes the $i$-th species, in this case $\mathrm{H}_{2} \mathrm{O}_{2}$ or $\mathrm{O}_{3}$ ). The $\mathrm{O}_{3}$ solubility is low and there are enough species in the gas phase to achieve the saturated concentration in the water, i.e., the saturation degree $\xi_{i}$ defined as $\xi_{i}(t)=c_{i}(t) / c_{i}^{\text {satur }}$, can approach one, without significant depletion of $\mathrm{O}_{3}$ gas density. It should be noted that the decrease of $\mathrm{O}_{3}$ concentration in the gas phase was not measurable at the resolution of $0.3 \mathrm{ppm}$ by the used $\mathrm{O}_{3}$ gas sensor.

On the other hand, a measurable depletion of $\mathrm{H}_{2} \mathrm{O}_{2}$ in the gas phase was observed, both in the bulk and ES experiments. This is in agreement with the modeling results presented in [57,58]. The measured molar amount (number of moles) of dissolved $\mathrm{H}_{2} \mathrm{O}_{2}$ fits well with the molar amount of $\mathrm{H}_{2} \mathrm{O}_{2}$ depleted from the gas phase (Figure 8c,d) within the experimental uncertainty. The insufficient amount of $\mathrm{H}_{2} \mathrm{O}_{2}$ remaining in the gas phase is the factor limiting the $\mathrm{H}_{2} \mathrm{O}_{2}$ concentration achievable in the liquid phase.

There are simply not enough $\mathrm{H}_{2} \mathrm{O}_{2}$ molecules in the gas phase to reach the saturated concentration in water. The saturated $\mathrm{H}_{2} \mathrm{O}_{2}$ concentration in liquid water is $\sim 10 \mathrm{M}$. With the gaseous concentration of $\mathrm{H}_{2} \mathrm{O}_{2} \sim 100 \mathrm{ppm}\left(\sim 2.46 \times 10^{15} \mathrm{~cm}^{-3}\right)$, approximately $6 \times 10^{21}$ molecules must be dissolved to achieve saturation in the used reactor and more than 
$2 \times 10^{3} \mathrm{~L}$ of the gas passing through the reactor would be needed. With the gas flow of $1 \mathrm{~L} / \mathrm{min}$ at input concentration $100 \mathrm{ppm}$, even if assumed that all $\mathrm{H}_{2} \mathrm{O}_{2}$ is dissolved and nothing leaves out from the reactor, such an experiment would take more than $30 \mathrm{~h}$. During the experiment with 2 min treatment time, the highest achievable concentration is thus in the order of $10^{-3}$ of the saturated concentration, i.e., the $\mathrm{H}_{2} \mathrm{O}_{2}$ saturation degree $\xi_{\mathrm{H} 2 \mathrm{O} 2}$ reaches the order of 0.001 only (Figure 9).

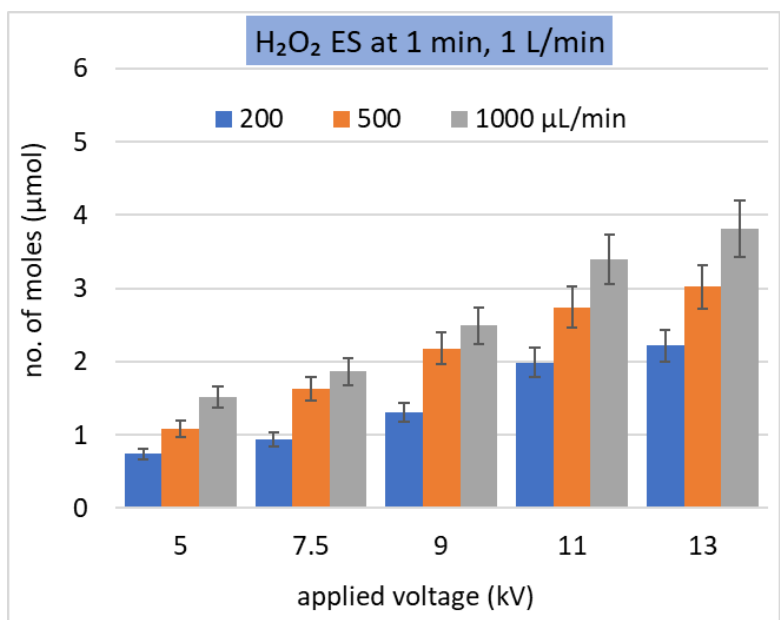

(a)

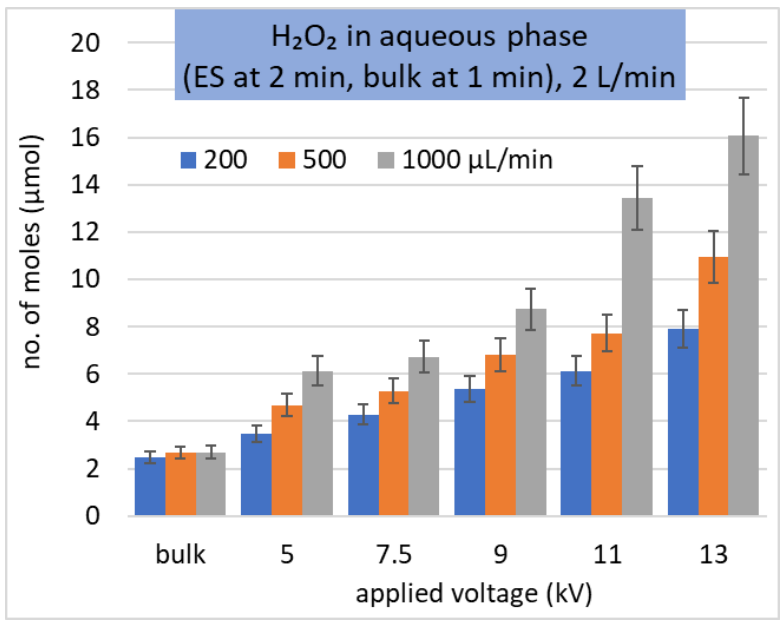

(c)

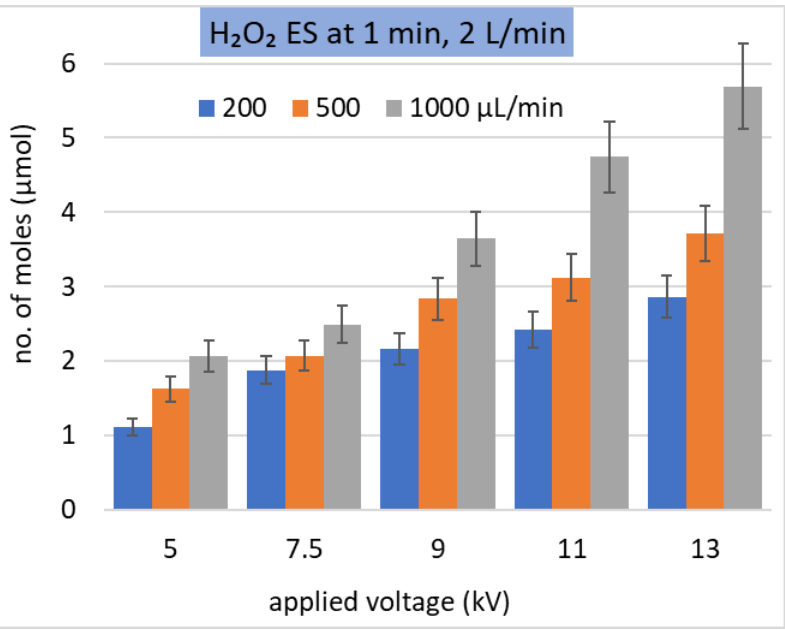

(b)

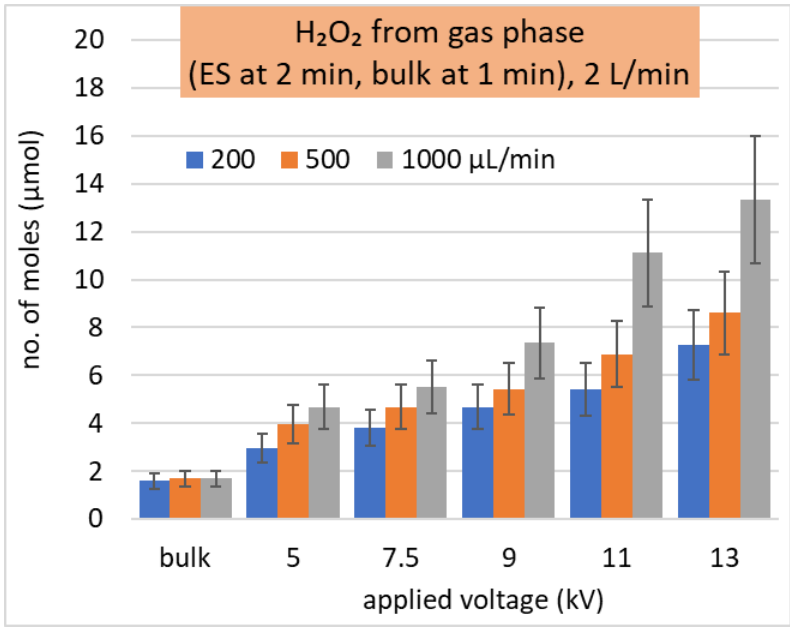

(d)

Figure 8. Solvation of $\mathrm{H}_{2} \mathrm{O}_{2}$ as the molar number of dissolved molecules in ES. (a,b) different gas flow rates (L/min) and $Q_{w}(\mu \mathrm{L} / \mathrm{min})$ during 1 min treatment time; (b,c) the same gas flow rate $2 \mathrm{~L} / \mathrm{min}$ and different treatment times (min) in ES and in (c) also bulk water added; (d) depleted $\mathrm{H}_{2} \mathrm{O}_{2}$ from the gas at the conditions of (c).

In reality, not all of the $\mathrm{H}_{2} \mathrm{O}_{2}$ molecules passing through the reactor can be dissolved. The solvation efficiency $\eta_{\mathrm{H} 2 \mathrm{O} 2}$, which determines how many of the total $\mathrm{H}_{2} \mathrm{O}_{2}$ molecules from the gas are dissolved with respect to all available $\mathrm{H}_{2} \mathrm{O}_{2}$ molecules, was as high as 0.5 in the bulk experiment. This result indicates that $\mathrm{H}_{2} \mathrm{O}_{2}$ is well soluble even in bulk water and so it is not possible to increase it substantially by the ES. Figure 10 shows the solvation efficiency obtained in the $\mathrm{H}_{2} \mathrm{O}_{2}$ ES experiment with $Q_{w} 200,500$, and $1000 \mu \mathrm{L} / \mathrm{min}$, treatment time $1 \mathrm{~min}$, at the gas flow rate $1 \mathrm{~L} / \mathrm{min}$. If the bulk liquid experiment with $500 \mu \mathrm{L}$ of water where $\eta_{\mathrm{H} 2 \mathrm{O} 2} \approx 0.52$ is compared with the ES experiment (Figure 10), at $7.5 \mathrm{kV}$ and $Q_{w}=500 \mu \mathrm{L} / \mathrm{min}$, the solvation efficiency is also only around 0.5 . 


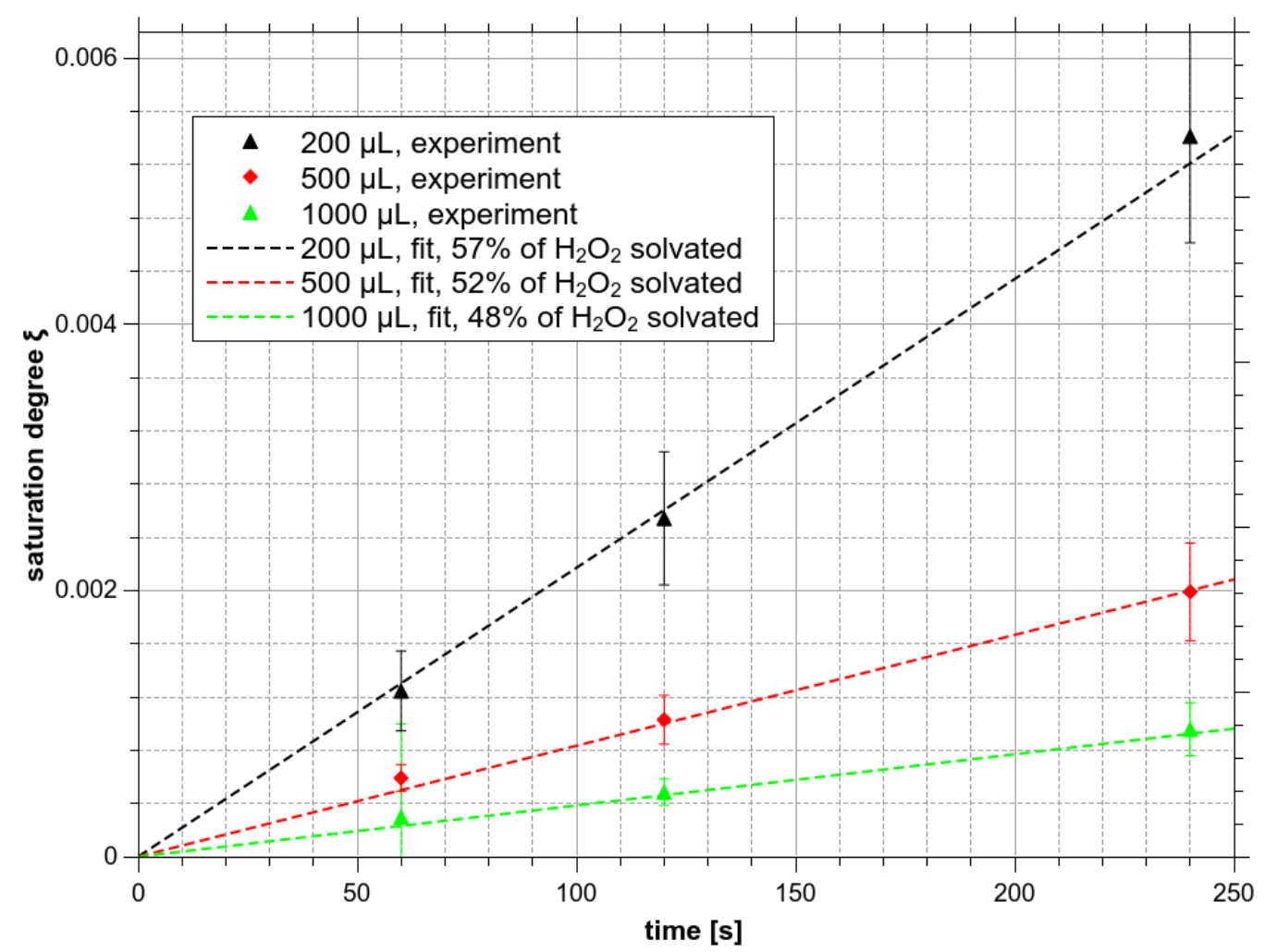

Figure 9. Saturation degree $\xi_{\mathrm{H} 2 \mathrm{O} 2}$ of $\mathrm{H}_{2} \mathrm{O}_{2}$ as a function of treatment time and bulk water volume.

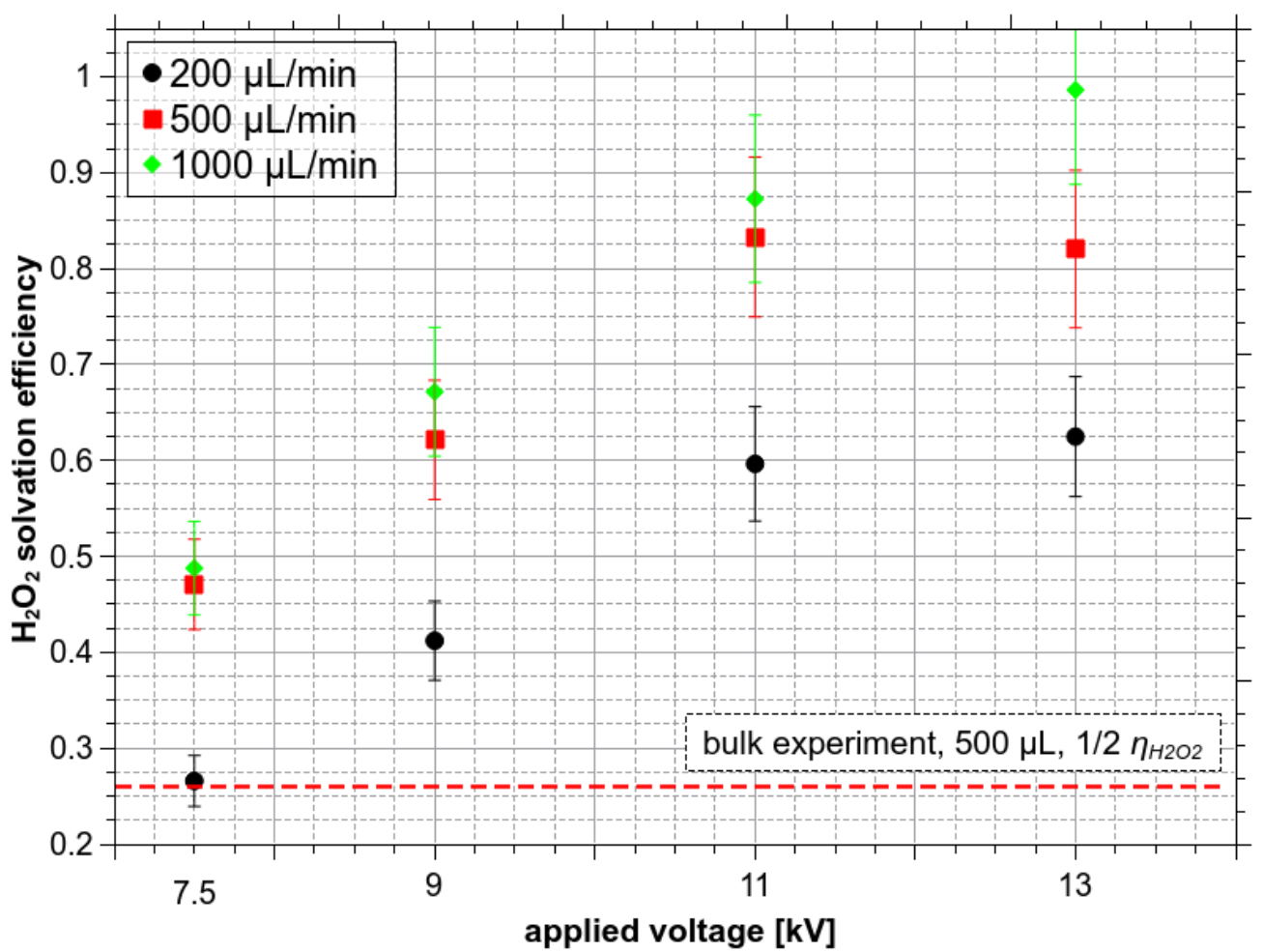

Figure 10. Solvation efficiency of $\mathrm{H}_{2} \mathrm{O}_{2}$ at a gas flow of $1 \mathrm{~L} / \mathrm{min}$ as a function of $V_{a}(\mathrm{kV})$, treatment time 1 min, at different $Q_{w}(\mu \mathrm{L} / \mathrm{min})$.

However, it should be emphasized that in the ES experiments, the water is sprayed into the reactor gradually, while in the bulk experiments all the water is inside the reactor 
all the time since the start. The average time during the water is exposed to the gaseous $\mathrm{H}_{2} \mathrm{O}_{2}$ in the ES experiment is only a half of the treatment time of the bulk experiment. Thus, it is more reasonable to compare the solvation efficiency from the ES experiments with a half of the solvation efficiency obtained in the bulk liquid experiments (Figure 10). Thus, even at low voltage $7.5 \mathrm{kV}$, the enhancement of $\mathrm{H}_{2} \mathrm{O}_{2}$ solvation was achieved in the ES compared to the bulk.

Even if ES solvation efficiency is compared to a half of the bulk solvation efficiency $(\sim 0.25)$, the maximum theoretical achievable enhancement by the ES is by a factor of four. The full potential of solvation enhancement by microdroplets cannot be therefore demonstrated on $\mathrm{H}_{2} \mathrm{O}_{2}$ due to its extremely high solubility, causing its depletion in the gas phase and achieving 50\% solvation efficiency even in the bulk experiment. In the next sections, the focus will be therefore on the $\mathrm{O}_{3}$ molecule with poor solubility, where a higher increase of the dissolved molecules was achieved in the ES (Figure 7c,d).

The highest $\mathrm{O}_{3}$ concentration in water was obtained in the ES experiment at $Q_{w}=1000 \mu \mathrm{L} / \mathrm{min}$, where $\sim 10$ times more $\mathrm{O}_{3}$ was dissolved compared to the bulk liquid experiment. However, the total interface area of microdroplets was augmented much more (the highest measured total surface area augmentation factor was 190 at $13 \mathrm{kV}$ and $500 \mu \mathrm{L} / \mathrm{min}$ ). This means that the surface area augmentation is not the only important parameter to be considered when comparing the ES and the bulk liquid solvation. Another important parameter is the interaction time.

During the ES process, the microdroplets fly from the needle nozzle towards the bottom of the reactor. Thus, the relevant lifetime of the microdroplets is not the duration of the experiment, but the time between their formation and the moment when they hit the bottom of the reactor. The lifetime of these microdroplets can be calculated from their traveled path and their speed $v_{d}$. Figure 11 shows the distribution of their speed as a function of their diameter, as measured by the HS camera. The shortest possible path of a droplet moving perpendicularly to the ground is $2.5 \mathrm{~cm}$, but the real path of a droplet deviated from the axis of the reactor can be as long as $\sim 3 \mathrm{~cm}$. For the biggest and the slowest microdroplets $\left(v_{d} \sim 3.5 \mathrm{~m} / \mathrm{s}\right)$, the longest lifetime up to $\sim 9 \mathrm{~ms}$ can be reached.

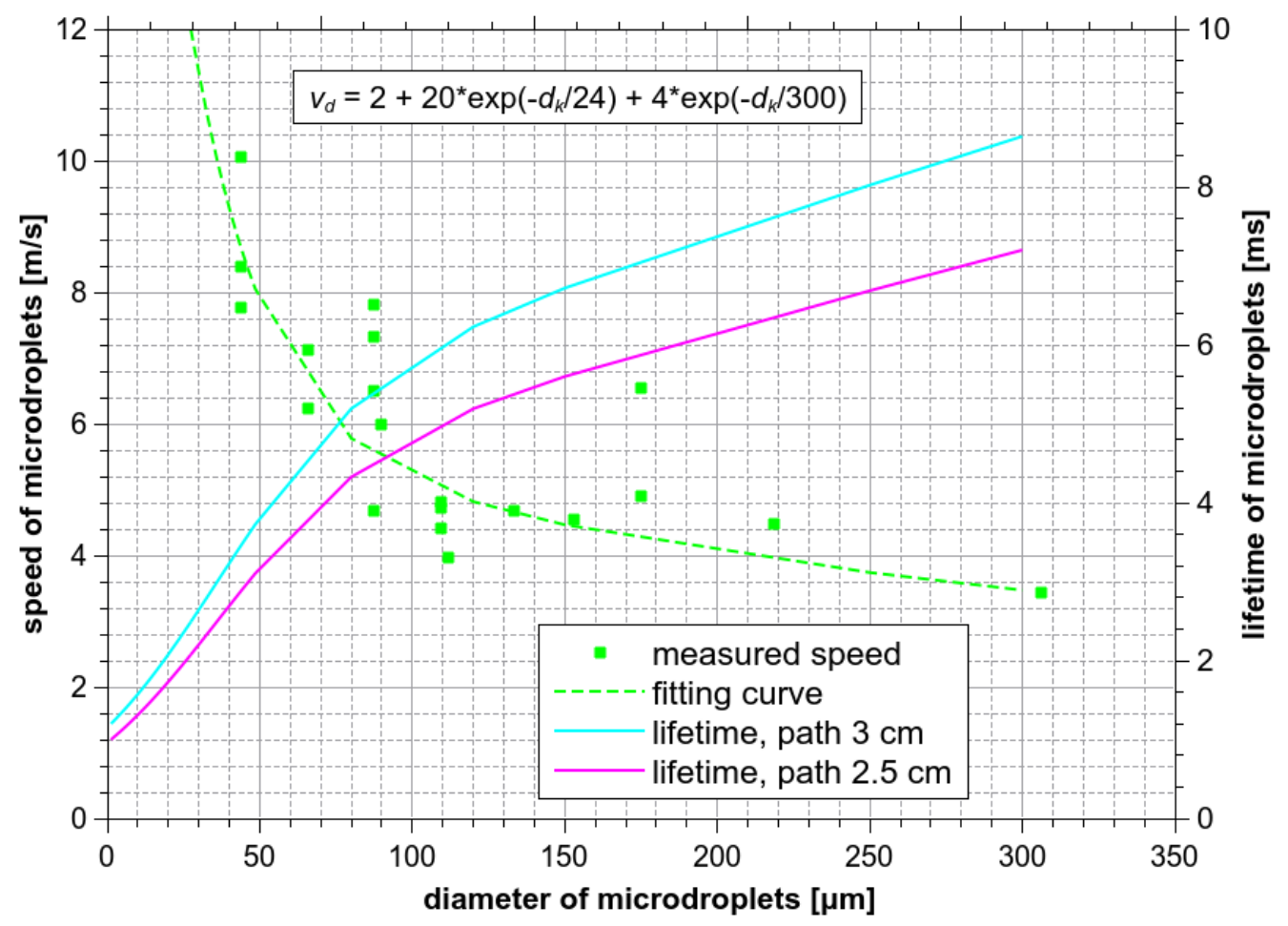

Figure 11. Speed of the ES microdroplets measured from the HS camera images and their lifetime as a function of their diameter $d_{k}$. 
Compared to the interaction (i.e., treatment) time in the bulk experiment (1-4 min, i.e., order of $100 \mathrm{~s}$ ), the lifetime of flying microdroplets is by $4-5$ orders of magnitude shorter. Considering that the total surface area of ES microdroplets is augmented much less compared to the bulk with respect to their much shorter lifetime, one should in fact expect a lower amount of dissolved $\mathrm{O}_{3}$ into the ES droplets than in the bulk water. This contradicts the experimental results. To resolve this problem, it is necessary to consider the effect of microdroplets which stay as separated microdroplets for a certain time even after they hit the bottom of the reactor. They can stay at the bottom for a much longer time than just a few milliseconds before they merge to form bigger droplets and eventually a uniform bulk liquid.

In the real ES experiment with a constant $Q_{w}$ running for a specific treatment time, the total amount of dissolved $\mathrm{O}_{3}$ (and $\mathrm{H}_{2} \mathrm{O}_{2}$ ) molecules is given by the sum of those dissolved during the short lifetime of flying microdroplets, then the molecules absorbed by microdroplets sitting at the bottom of the reactor, and finally by merged bigger droplets (eventually forming bulk liquid) formed later during the experiment. There are also some microdroplets sprayed onto the walls of the reactor during the ES process. The amount of these sprayed droplets is increased with the increase of $Q_{w}, V_{a}$, and the treatment time. Contribution of various phases (flying, bottom, and sprayed droplets, besides the formed bulk) to $\mathrm{O}_{3}$ solvation into the liquid water will be discussed in the next subsection, based on a comparison of theoretical calculations with the experimental results.

\subsection{Mass Transfer of Ozone from Gas to the Liquid Phase. The Role of Surface Area}

In the simplified theory outlined in Section 2, Equation (8) which can be used to describe the dynamics of the microdroplets solvation was derived. Equation (8) is valid both for bulk liquid as well as for microdroplets. If only spherical droplets with diameter $d_{k}$, are considered, an expression where $m_{\mathrm{O}}$ is the mass of $\mathrm{O}_{3}$ molecules and $\tau$ is characteristic Henry's law equilibration time can be finally derived:

$c_{\mathrm{O} 3}(t)=p_{\mathrm{O} 3} k_{H}^{\mathrm{O} 3}\left(1-\exp \left(\frac{-6 t}{N_{A} d_{k} k_{H}^{\mathrm{O} 3} \sqrt{2 \pi m_{\mathrm{O} 3} k_{B} T}}\right)\right)=p_{\mathrm{O} 3} k_{H}^{\mathrm{O} 3}\left(1-\exp \left(\frac{-t}{\tau}\right)\right)$.

It shows that the aqueous ozone concentration $c_{\mathrm{O} 3}(t)$ converges towards a saturated concentration $c_{\mathrm{O} 3}^{\text {satur. }}$. with the increasing time. In the simplified theory used to derive this equation, it was assumed that the partial pressure of $\mathrm{O}_{3}$ did not change in time and that the concentration in the liquid phase was homogeneous. The real situation is more complicated, and this simple solvation theory is not sufficient. Equation (9) predicts very fast saturation of water by dissolved ozone even for large droplets with $d_{k}=3 \mathrm{~mm}$. The characteristic Henry's law equilibration time predicted by this theory is much shorter than $\tau$ obtained by the more sophisticated model presented by Kruzselnicki et al. [57].

The first assumption in this model, the constant density of $\mathrm{O}_{3}$ in the gas phase, is in agreement with the results presented in the literature $[57,58]$. For this reason, the major problem of the above theoretical considerations was supposed as the assumption that the dissolved molecules spread immediately inside the entire droplet. It is probably only a thin gas/liquid interface, with a characteristic width of several nanometers [62-65], that becomes saturated quickly. To correct this theory, the fact that the dissolved $\mathrm{O}_{3}$ concentration inside the liquid equalizes only very slowly by diffusion must be accounted for. First, the solvation with diffusion into the bulk liquid will be discussed, where the calculations are simpler because it can be considered as a one-dimensional problem.

\subsection{1. $\mathrm{O}_{3}$ Diffusion into the Bulk Liquid}

In a one-dimensional situation (bulk liquid) the distance $L$ to which $\mathrm{O}_{3}$ will diffuse during a given time can be estimated by a simple equation

$$
L \sim \sqrt{2 D_{\mathrm{O} 3} t}
$$


where $D_{\mathrm{O} 3}$ is the diffusion coefficient of $\mathrm{O}_{3}$ in water. At $300 \mathrm{~K}, D_{\mathrm{O} 3}=2 \times 10^{-5} \mathrm{~cm}^{2} / \mathrm{s}$ [66]. To simplify the calculation, it can be assumed that the surface area is quickly saturated by dissolved $\mathrm{O}_{3}$ molecules and their concentration there can be considered as constant $\left(c_{\mathrm{O} 3}^{\text {satur. }}\right)$. The one-dimensional theory of diffusion can be used to describe the concentration evolution in time and depth $h$ of the bulk liquid.

$$
c_{\mathrm{O} 3}(h, T)=c_{\mathrm{O} 3}^{\text {satur }} \exp \left(\frac{-h^{2}}{4 D_{\mathrm{O} 3} t}\right) .
$$

Integration from 0 to $H$ (the total depth of the bulk liquid) gives the average concentration in each time, and hence the degree of saturation $\xi_{\mathrm{O}}$ as a function of time and $\mathrm{H}$ (Equation (12))

$$
\xi_{\mathrm{O} 3}(H, t)=\frac{\int_{0}^{H} \exp \left(\frac{-h^{2}}{4 D_{\mathrm{O} 3} t}\right) \mathrm{d} x}{H} .
$$

Figure 12 shows the calculated saturation degree time evolutions for three different values of the bulk water depths $H: 1.51,3.77$, and $7.54 \mathrm{~mm}$ (they correspond to the water volumes 200, 500, and $1000 \mu \mathrm{L}$ in the bulk reactor, respectively). With $H=3.77 \mathrm{~mm}$ and the treatment time $4 \mathrm{~min}(240 \mathrm{~s})$, the theoretical average concentration of $\mathrm{O}_{3}$ should reach only about $32 \%$ of the saturation level. For $H=7.54 \mathrm{~mm}$, this number is even lower (16\%). The theoretical curves are compared with experimental results in Figure 12. There is a relatively good agreement within the experimental uncertainty, except for $H=1.51 \mathrm{~mm}$, where experimental values are below the theoretical ones. At $H=1.51 \mathrm{~mm}$ the volume of water is very small $(200 \mu \mathrm{m})$. Even slight vibrations and shivering of the water surface due to the gas flow can have a significant influence on the $\mathrm{O}_{3}$ solvation inside the bulk liquid.

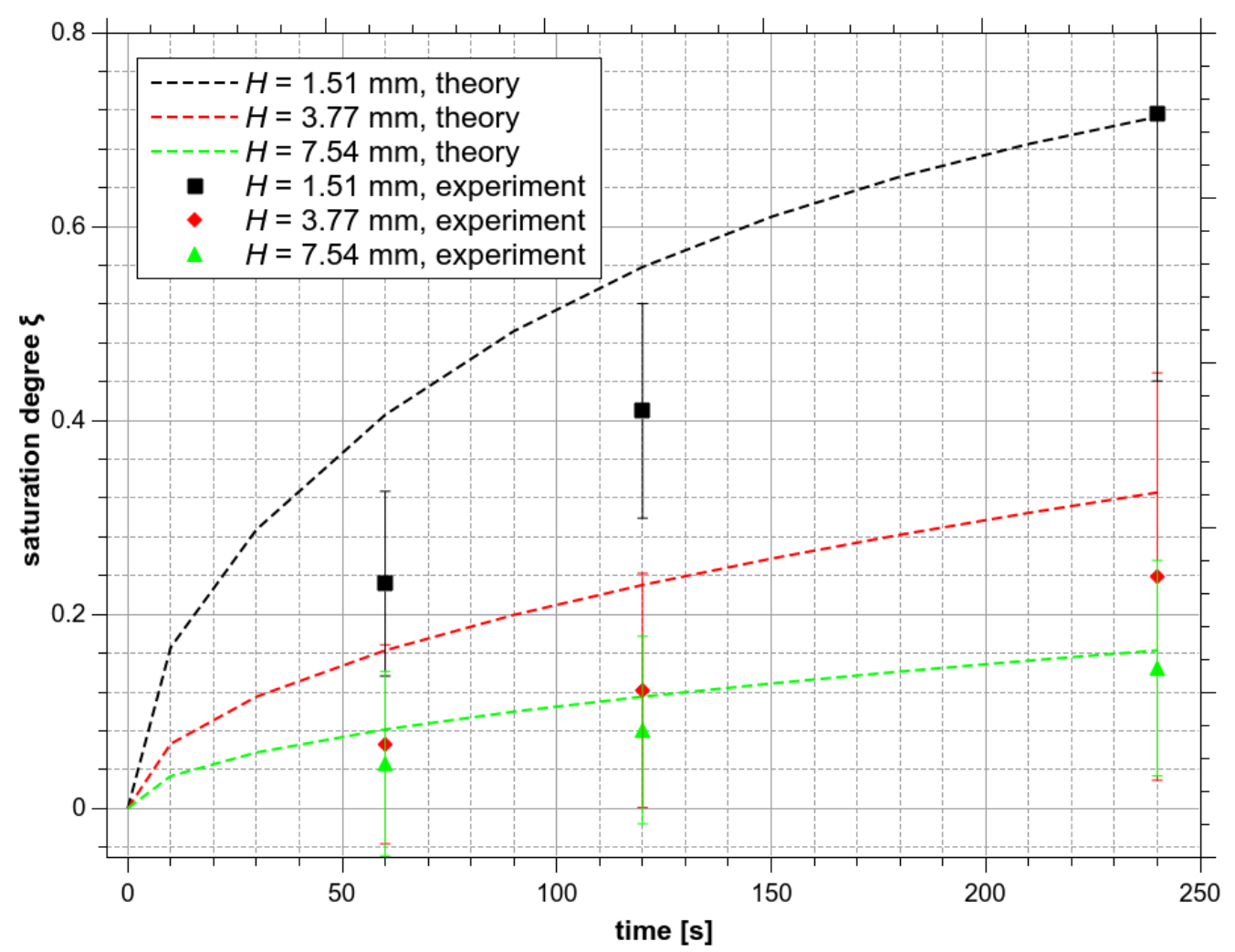

Figure 12. Saturation degree $\xi_{\mathrm{O} 3}$ of $\mathrm{O}_{3}$ as a function of treatment time and the bulk water depth $H$. 


\subsection{2. $\mathrm{O}_{3}$ Diffusion into Microdroplets}

Like in the bulk liquid, the calculation in ES microdroplets is easier under an assumption that the surface area is quickly saturated by $\mathrm{O}_{3}$ molecules and the concentration here can be considered as constant $\left(c_{\mathrm{O} 3}^{\text {satur }}\right)$. Next, the saturation degree $\xi_{\mathrm{O} 3}$ in the droplets as a function of time and $r_{k}$ (droplet radius) is estimated. The concentration of dissolved $\mathrm{O}_{3}$ inside the droplet as a function of time and a radial coordinate $r$ is approximated by the function

$$
c_{\mathrm{O} 3}(r, t)=c_{\mathrm{O} 3}^{\text {satur. }} \cdot \exp \left(\frac{-\left(r_{k}-r\right)^{2}}{4 D_{\mathrm{O} 3} t}\right) .
$$

The saturation degree by ozone $\xi_{\mathrm{O} 3}$ as a function of time and $r_{k}$ in spherical coordinates can be then calculated by Equation (14)

$$
\xi_{i}(r, t)=\frac{3 \times \int_{0}^{r_{k}} r^{2} \exp \left(\frac{-\left(r_{k}-r\right)^{2}}{4 D_{i} t}\right) \mathrm{d} r}{r_{k}^{3}} .
$$

Figure S1 (Supplementary Materials) shows the estimated $\mathrm{O}_{3}$ saturation degree for flying microdroplets with different diameters in the time scale up to $10 \mathrm{~ms}$, which is approximately the longest expected lifetime of the generated microdroplets (Figure 11). The increase of $\xi_{\mathrm{O} 3}$ calculated by Equation (14) (Figure S1) can be approximated by a formula equivalent to Equation (9) with much longer characteristic Henry's law equilibration time $\tau$. Kruzselnicki et al. calculated $\tau$ to be approximately 30,100 , and $300 \mu$ s for microdroplets with diameters 30,100 , and $300 \mu \mathrm{m}$, respectively [57]. The values obtained by our approach are approximately one order of magnitude higher. However, characteristic Henry's law equilibration time $\tau$ from the model of Kruzselnicki et al. [57] is not in good agreement with the presented experimental data. The microdroplets lifetime above $1 \mathrm{~ms}$ (Figure S1) was observed and almost all of them had a diameter below $300 \mu \mathrm{m}$ (Figure 5). According to $\tau$ from the model of [57], microdroplets would be saturated by $\mathrm{O}_{3}$ relatively shortly after the moment when they are created, long before they hit the reactor bottom. In such a case, water saturated by $\mathrm{O}_{3}$ would be always collected and no dependence of the measured $\mathrm{O}_{3}$ concentration in the water on the applied voltage and water flow rate would be detected (Figure 7). It can be thus assumed that our estimate of $\tau$ supported by the experiments is more realistic.

Based on the obtained results (Figure S1), it can be concluded that only very small microdroplets with a diameter below $\sim 40 \mu \mathrm{m}$ could be saturated within this timescale of $\sim 10 \mathrm{~ms}$. To achieve the highest solvation rate, it would be preferable if all droplets had this or a lower diameter. The obtained measurements show that most of the detected droplets have a slightly larger diameter, around $50 \mu \mathrm{m}$ (Figure 5). In real ES, the average size of the microdroplets might be even smaller, because it was not possible to detect droplets with a diameter below $\sim 20 \mu \mathrm{m}$ by the used imaging technique with the resolution of $21.875 \mu \mathrm{m} /$ pixel.

However, the droplet size distribution histograms shown in Figure 5 do not reflect that the overall saturation degree depends significantly on the volume of droplets. If 10 tiny ozone-saturated droplets $\left(d_{k}=10 \mu \mathrm{m}\right)$ were merged with 1 larger droplet with $d_{k}=200 \mu \mathrm{m}$ and $\xi_{O 3}=0.1$, the resulting $\xi_{O 3}$ would be only 0.100125 , i.e., dominated by the large droplet. For this reason, data from Figure 5 a have been recalculated to show the relative contribution of droplets with different diameters to the total volume $P^{v}\left(d_{k}\right)$. In this representation (Figure 13), the contribution of the tiny droplets is minimal. 


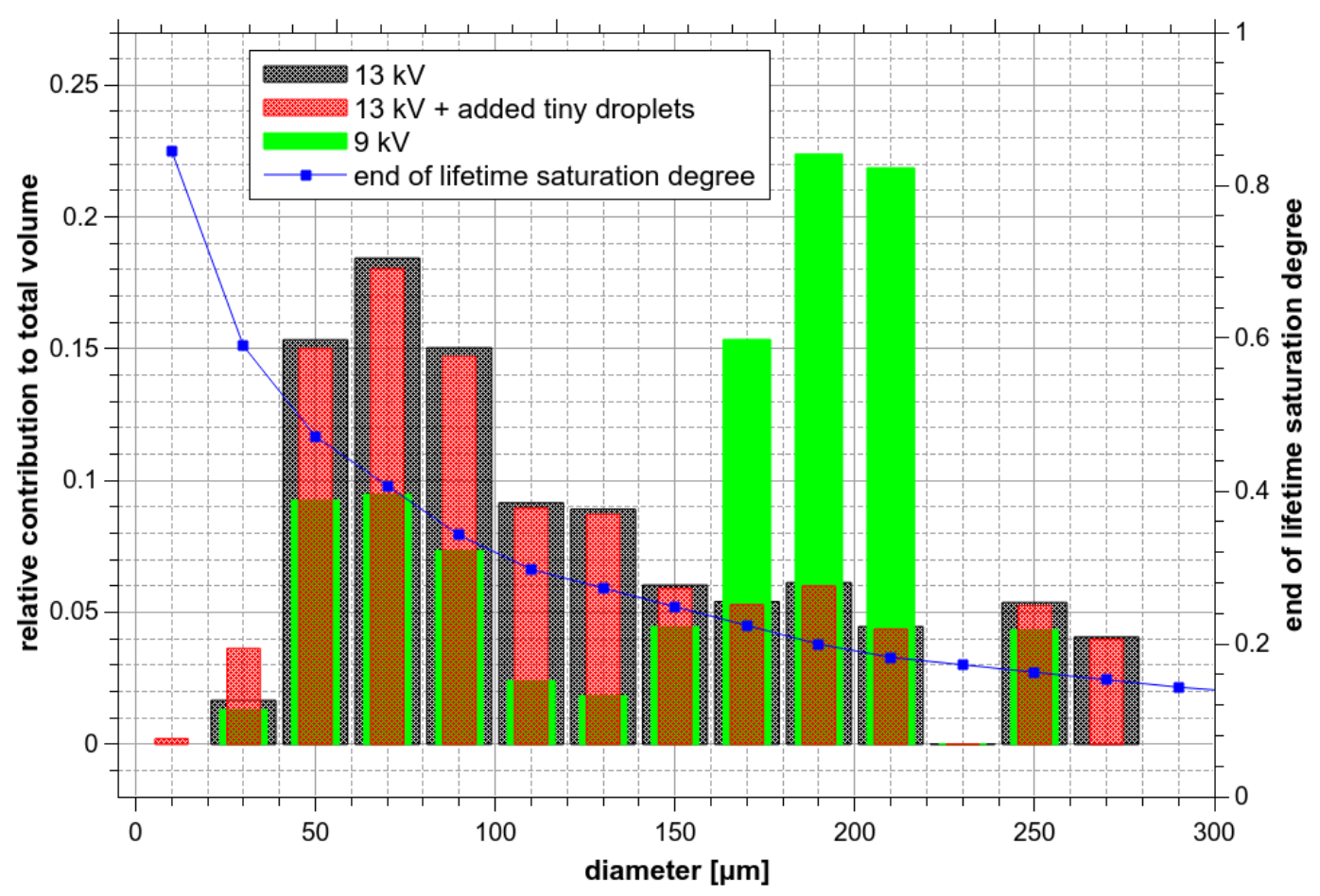

Figure 13. Relative contribution of the droplets with different diameters to the total volume $P^{v}\left(d_{k}\right)$ and saturation degree at the end of their lifetime $\xi^{f i n}\left(d_{k}\right)$ as a function of droplet diameter, $V_{a}=9$ and $13 \mathrm{kV}, Q_{w}=300 \mu \mathrm{L} / \mathrm{min}$.

For verification, the size distribution histogram measured at $13 \mathrm{kV}$ and $300 \mu \mathrm{L} / \mathrm{min}$ was artificially modified. The number of small microdroplets with a diameter of $20-40 \mu \mathrm{m}$ was doubled and droplets with a diameter below $20 \mu \mathrm{m}$ were added as if their relative abundance were $\sim 37 \%$. Nevertheless, the influence of this modification on $P^{v}\left(d_{k}\right)$ was almost negligible (Figure 13). A significant difference between $P^{v}\left(d_{k}\right)$ at 9 and $13 \mathrm{kV}$ can be seen, although the difference between 9 and $13 \mathrm{kV}$ seemed to be negligible in the original droplet size distribution histogram (Figure 5a).

Figure 13 also shows $\xi^{f i n}\left(d_{k}\right)$, the saturation degree of $\mathrm{O}_{3}$ at the end of the droplet lifetime (Figure 11, path $3 \mathrm{~cm}$ ) as a function of droplets diameter. Finally, the effective saturation degree $\xi^{\text {eff }}$ of droplets hitting the bottom of the reactor can be defined by integrating the product of $P^{v}\left(d_{k}\right)$ with $\xi^{f i n}\left(d_{k}\right)$ over the entire range of diameters:

$$
\xi^{e f f}=\int_{d_{k}} \xi^{f i n}\left(d_{k}\right) P^{v}\left(d_{k}\right) \mathrm{d} d_{k}
$$

Figure 14 shows the $\xi^{\text {eff }}$ calculated for all $V_{a}$ and $Q_{w}$, which increases with the applied voltage that shifts the relative contribution distribution towards the smaller diameter droplets (Figure 13). As Figure 14 shows, there is no significant dependence of $\xi^{\text {eff }}$ on the $Q_{w}$, though $\tilde{\zeta}^{\text {eff }}$ is probably slightly smaller at $500 \mu \mathrm{L} / \mathrm{min}$ than at lower $Q_{w}$. This could mean slightly bigger droplets on average. On the other hand, $\xi^{\text {eff }}$ calculated at $100 \mu \mathrm{L} / \mathrm{min}$ is probably slightly higher than at higher $Q_{w}$, except for $V_{a}=13 \mathrm{kV}$, when the formation of microdroplets was most probably influenced by the onset of corona discharge. The increase of $\xi^{e f f}$ with increasing $V_{a}$ can partly explain the increase of the dissolved $\mathrm{O}_{3}$ amount with increasing $V_{a}$ (Figure 7). For a more precise explanation of the observed dependence of solvation on $V_{a}$, the microdroplets sitting at the bottom must be also considered. 


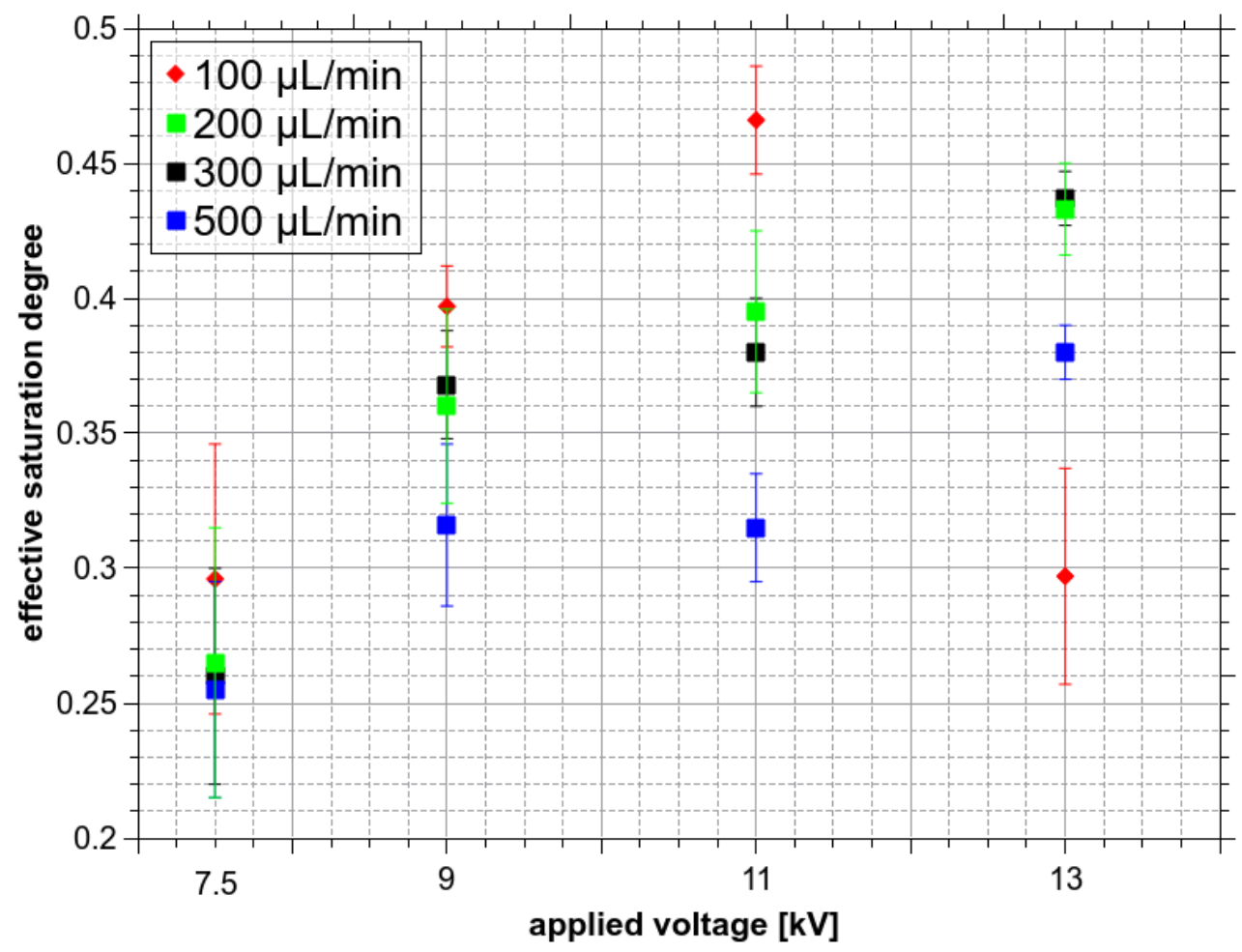

Figure 14. Effective $\mathrm{O}_{3}$ saturation degree $\xi^{\text {eff }}$ of flying microdroplets as a function of $V_{a}(\mathrm{kV})$ at different $Q_{w}(\mu \mathrm{L} / \mathrm{min})$.

To estimate the role of microdroplets sitting at the bottom of the reactor, some simplifications should be considered. We will consider these bottom microdroplets to be semi-spheres (with a contact angle $90^{\circ}$ ) having the same volume as their parent microdroplets from the ES. Consequently, their diameter $d_{s}$ will be slightly bigger than the diameter of their parent microdroplets $\left(d_{s} \sim 1.26 d_{k}\right)$. Next, the saturation degree reached in these bottom microdroplets can be estimated if their lifetime $\left(\tau_{s}\right)$ is known. Water flow rate $Q_{w}$ is constant during the experiment and if they do not coagulate, their average lifetime would be equal to half of the total treatment time. Thus, for the $Q_{w}$ of $200 \mu \mathrm{L} / \mathrm{min}$, the total water volume $1 \mathrm{~mL}$ would be collected at the bottom in $5 \mathrm{~min}(300 \mathrm{~s})$ and the average lifetime of bottom microdroplets would be $150 \mathrm{~s}$.

In the ES experiment, the droplets are sprayed into a relatively wide solid angle. As a result, they are distributed all over the reactor bottom (even walls) in the initial phase. Gradually, bigger droplets are being formed at places with the highest flux of merging droplets. This process decreases the average lifetime of bottom microdroplets. Moreover, as the reactor bottom gets gradually more and more covered by big droplets, more and more incoming microdroplets hit these big droplets instead of the clean surface of the reactor bottom, having thus the bottom lifetime $\tau_{s}=0 \mathrm{~s}$. A correct assessment of the bottom droplets' lifetime will require further studies. Here, as the first approximation, the saturation degree of the bottom microdroplets using $\tau_{s}$ up to $10 \mathrm{~s}$ was calculated from Equation (14). For $d_{s}=300 \mu \mathrm{m}$ (corresponding to the parent microdroplets with $d_{k}=238 \mu \mathrm{m}$ ), it is obtained that the saturation degree will exceed $90 \%$ within $\tau_{s}=10 \mathrm{~s}$, even starting from the saturation degree 0 (Figure S2 in Supplementary Materials). This shows that the solvation into bottom microdroplets plays a significant role in the experiment, even if their average lifetime is in the order of $1 \mathrm{~s}$, which is still much longer than the lifetime of flying microdroplets ( 10 ms).

4.4.3. Roles of Flying Microdroplets, Sitting Bottom Microdroplets vs. Solvation in the Formed Bulk

The calculated effective saturation degree $\xi^{\text {eff }}$ of flying microdroplets (Figure 14) could help to assess the importance of flying microdroplets vs. sitting bottom microdroplets vs. 
formed bulk water solvation of $\mathrm{O}_{3}$. $\xi^{\text {eff }}$ to the measured $\xi_{\mathrm{O} 3}$ values should be compared under various experimental conditions. It is demonstrated in Figure 15.

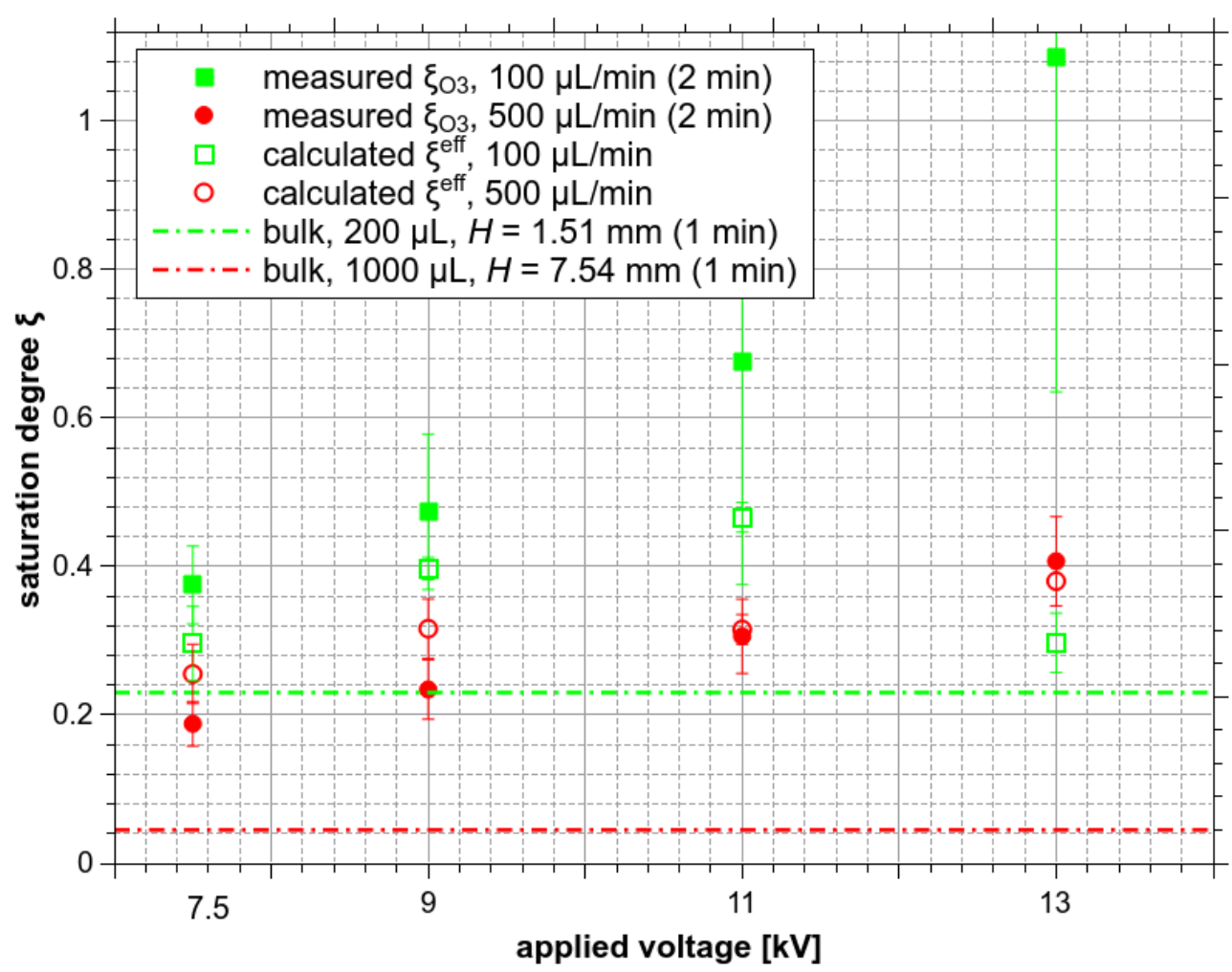

Figure 15. Comparison of $\mathrm{O}_{3} \xi^{\text {eff }}$ calculated from the size distribution histograms (Figure 5) of flying microdroplets with the measured $\xi_{\mathrm{O} 3}$ of bottom microdroplets of two sets of ES experiments $\left(Q_{w}=100\right.$ and $\left.500 \mu \mathrm{L} / \mathrm{min}\right)$, and $\mathrm{O}_{3}$ saturation in the corresponding bulk experiments.

First, by looking at the ES experiment with $Q_{w}$ of $500 \mu \mathrm{L} / \mathrm{min}$ and a treatment time of $2 \mathrm{~min}$, the total amount of collected water is $1000 \mu \mathrm{L}$. $Q_{w}$ is relatively high, and the bulk liquid is quickly formed and then exists during most of the treatment time. The contribution of bottom microdroplets should be thus small. The contribution of the solvation in the formed bulk can be estimated from the experiment with bulk water with volume $1000 \mu \mathrm{L}$ $(H=7.54 \mathrm{~mm}$ ) and the duration $1 \mathrm{~min}$ (half of the ES experiment time, because in the ES experiment the average water residence time inside the reactor is half of the treatment time), where the saturation degree only around 0.045 was achieved (red dashed line at the bottom of Figure 15). Thus, in the ES experiment even at low $V_{a}=7.5 \mathrm{kV}$, where $\xi_{\mathrm{O} 3}$ is significantly higher $(\sim 0.25)$ than in the bulk (0.045), the saturation must be mostly achieved, thanks to the flying microdroplets. This can explain a good correlation between the measured $\xi_{\mathrm{O} 3}$ and $\xi^{\text {eff }}$ for $Q_{w}=500 \mu \mathrm{L} / \mathrm{min}$ in Figure 15.

Second, let us consider the ES experiment with the $Q_{w}$ only $100 \mu \mathrm{L} / \mathrm{min}$, with no formed bulk and no big droplets formation during most of the treatment time. Thus, the contribution of bottom droplets should be crucial, while the contribution of the $\mathrm{O}_{3}$ solvation into the formed bulk should be small, although, in the bulk water experiment with the volume $200 \mu \mathrm{L}(H=1.51 \mathrm{~mm})$ and duration $1 \mathrm{~min}$, the saturation degree $\xi_{\mathrm{O} 3} \approx 0.23$ was achieved. In the ES experiment, even at low $V_{a} 7.5 \mathrm{kV}, \xi_{O 3}$ reached almost 0.4. The formed bulk solvation contribution would be even less important at higher $V_{a}$, where the advantage of flying and bottom microdroplets is already clearly visible because $\xi_{\mathrm{O} 3}$ grows with increasing $V_{a}$ up to $1.12 \pm 0.57$. When comparing the ES experiment with $Q_{w}=500 \mu \mathrm{L} / \mathrm{min}$ and $100 \mu \mathrm{L} / \mathrm{min}$, the significant increase of $\xi_{O 3}$ should be mostly due to the sitting bottom droplets. This also explains a high experimental uncertainty of the 
measured $\xi_{\mathrm{O}}$. The coagulation of microdroplets and big droplet formation is significantly different in each individual experiment.

\section{Conclusions}

Motivated by the increasing interest in plasma-liquid interactions and their applications, and knowledge gaps in the detailed understanding of the reactive species transport into liquids, the objective of this article was to investigate the transport of the most typical air plasma reactive species $\left(\mathrm{O}_{3}\right.$ and $\left.\mathrm{H}_{2} \mathrm{O}_{2}\right)$ into water. Solvation experiments with single $\mathrm{O}_{3}$ and $\mathrm{H}_{2} \mathrm{O}_{2}$ species in the airflow were conducted and their transport into bulk water vs. electrosprayed aerosol microdroplets was analyzed.

The gas-water interface surface area and the treatment (interaction) time are shown to be the key parameters of determining the amount of dissolved $\mathrm{O}_{3}$ and $\mathrm{H}_{2} \mathrm{O}_{2}$ in the bulk water regardless of the water volume. About $10^{4}$ times more $\mathrm{H}_{2} \mathrm{O}_{2}$ than $\mathrm{O}_{3}$ was dissolved in the water despite the $10^{7}$ times larger Henry's law coefficient of $\mathrm{H}_{2} \mathrm{O}_{2}$ than that of $\mathrm{O}_{3}$. This is because the amount of gaseous $\mathrm{H}_{2} \mathrm{O}_{2}$ molecules next to the gas-water interface area, unlike $\mathrm{O}_{3}$ molecules, is strongly depleted.

The total surface area of electrosprayed water microdroplets and thus the dissolved $\mathrm{O}_{3}$ and $\mathrm{H}_{2} \mathrm{O}_{2}$ increased with the increasing applied voltage and water flow rate. However, the observed solvation effect cannot be explained simply by the measured droplet size distribution and their total surface area. The limitation in the ES experiment is a very short lifetime (up to $9 \mathrm{~ms}$ only) of the generated flying microdroplets. In addition to this very short flying phase of the ES microdroplets, other phases of their total interaction time with $\mathrm{O}_{3}$ and $\mathrm{H}_{2} \mathrm{O}_{2}$, such as microdroplets sitting at the reactor bottom (and walls) until they merge and progressively form the bulk strongly contribute to the solvation of $\mathrm{O}_{3}$ and $\mathrm{H}_{2} \mathrm{O}_{2}$ into the ES water.

The experimental results were confronted with simple theoretical considerations. For $\mathrm{O}_{3}$, where no significant depletion of the gaseous molecules occurs, the diffusion of dissolved $\mathrm{O}_{3}$ molecules inside the liquid limits the solvation. After accounting for this diffusion in the liquid, a reasonable agreement of the saturation time evolution was achieved with the bulk liquid experiment. For $\mathrm{O}_{3}$ solvation in electrosprayed water microdroplets, their lifetime, as well as their contribution to the total water volume depending on their size and abundance are the most important parameters. At all water flow rates, ES water microdroplets (both flying and bottom) play the key roles in the total solvation.

In summary, we experimentally demonstrated and theoretically explained that Henry's law coefficient is not the only important parameter determining the dissolution of highly and lowly soluble $\left(\mathrm{H}_{2} \mathrm{O}_{2}\right.$ and $\left.\mathrm{O}_{3}\right)$ gaseous species into the water. Other experimental parameters, such as the gas-liquid interface surface area, gas flow rate, and the treatment (interaction) time should be considered for their solvation in the bulk liquid. In the ES microdroplets, the applied voltage, the water flow rate, and the microdroplet contribution to the total water volume are important, too. Their roles on flying and bottom microdroplets and the formed bulk were established. However, more detailed experimental/theoretical studies of these individual phenomena influencing water solvation of each specific species are needed in the future.

The investigated physical parameters allow for controlling the solvation efficiency of $\mathrm{H}_{2} \mathrm{O}_{2}$ and $\mathrm{O}_{3}$ gases into water bulk and electrospray. Our findings contribute to a better understanding of the solvation process of different gaseous species and can lead to optimization of the water spray systems and plasma-water interaction systems and their working conditions for multiple applications. The results can be useful e.g., when designing water ozonizers that cope with a low and relatively slow $\mathrm{O}_{3}$ solvation: spraying water to fine aerosol microdroplets and extending their interaction time with the gaseous $\mathrm{O}_{3}$ results in more efficient $\mathrm{O}_{3}$ mass transfer. On the other hand, in plasma-liquid interactions and plasma-activated water production systems, it is important to dissolve the maximum of the available $\mathrm{H}_{2} \mathrm{O}_{2}$ with typically low gaseous concentrations and reach the highest possible $\mathrm{H}_{2} \mathrm{O}_{2}$ concentrations in the water. $\mathrm{H}_{2} \mathrm{O}_{2}$ saturation in water can be only reached in the 
optimized reactor with a strong $\mathrm{H}_{2} \mathrm{O}_{2}$ depletion from the gas using a minimal volume of aerosolized water.

Supplementary Materials: The following are available online at https:/ /www.mdpi.com/2073-444 $1 / 13 / 2 / 182 / s 1$, Figure S1: Estimated evolution of saturation degree $\xi_{\mathrm{O} 3}$ of $\mathrm{O}_{3}$ as a function of time and diameter of flying microdroplets $d_{k}$, calculated for $\mathrm{O}_{3}$ diffusion in the water microdroplets at 300 $\mathrm{K}$, time span up to $10 \mathrm{~ms}$. Figure S2: Estimated evolution of saturation degree $\xi_{\mathrm{O} 3}$ as a function of time and diameter of sitting bottom microdroplets $d_{s}$, calculated for $\mathrm{O}_{3}$ diffusion in the water at 300 $\mathrm{K}$, time span up to $10 \mathrm{~s}$.

Author Contributions: M.E.H. ran and processed the experiments with microdroplets by fast/HS camera, and the investigations of $\mathrm{H}_{2} \mathrm{O}_{2}$ and $\mathrm{O}_{3}$ solvation into bulk and electrosprayed water, and wrote the first draft of the manuscript; M.J. contributed to the microdroplet visualization experiments and wrote the theoretical parts in the results and discussion including the comparison of the experimental and theoretical results; Z.M. planned, organized, and supervised the research, and reviewed and edited the manuscript. All authors have read and agreed to the published version of the manuscript.

Funding: This work was supported by Slovak Research and Development Agency APVV-17-0382, APVV-0134-12 and SK-PL-18-0090, Slovak Grant Agency VEGA 1/0419/18, and Comenius University grants UK/317/2020 and UK/325/2019.

Institutional Review Board Statement: Not applicable.

Informed Consent Statement: Not applicable.

Data Availability Statement: Not applicable.

Acknowledgments: We thank Piotr Terebun, Michal Kwiatkowski, and Joanna Pawlat from Lublin University of Technology, Poland, for enabling us HS camera measurements.

Conflicts of Interest: The authors declare no conflict of interest in publishing this manuscript.

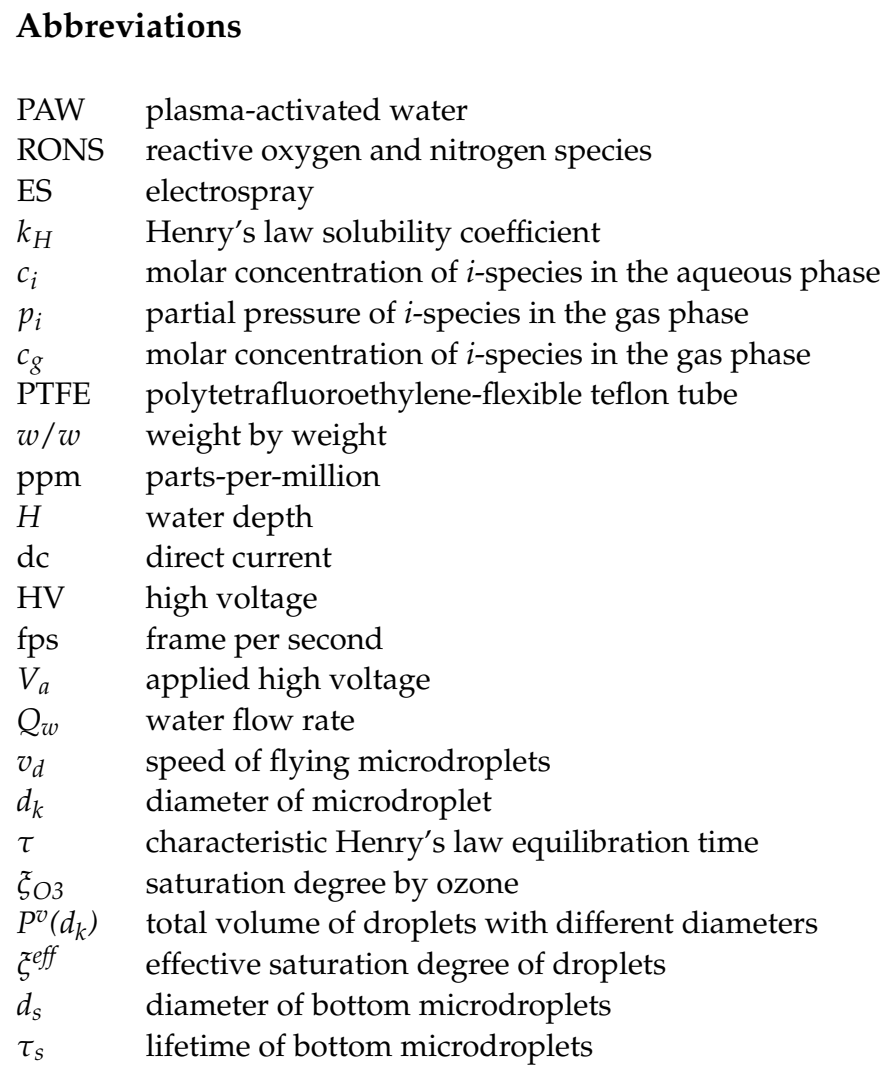




\section{References}

1. Bruggeman, P.; Leys, C. Non-thermal plasmas in and in contact with liquids. J. Phys. D Appl. Phys. 2009, 42, 053001. [CrossRef]

2. Rezaei, F.; Vanraes, P.; Nikiforov, A.; Morent, R.; De Geyter, N. Applications of Plasma-Liquid Systems: A Review. Materials 2019, 12, 2751. [CrossRef] [PubMed]

3. $\quad$ Bruggeman, P.J.; Kushner, M.J.; Locke, B.R.; Gardeniers, J.G.E.; Graham, W.G.; Graves, D.B.; Hofman-Caris, R.C.H.M.; Maric, D.; Reid, J.P.; Ceriani, E.; et al. Plasma-liquid interactions: A review and roadmap. Plasma Sources Sci. Technol. 2016, $25,053002$. [CrossRef]

4. Locke, B.R.; Sato, M.; Sunka, P.; Hoffmann, M.R.; Chang, J.S. Electrohydraulic discharge and nonthermal plasma for water treatment. Ind. Eng. Chem. Res. 2006, 45, 882-905. [CrossRef]

5. Locke, B.R. Environmental Applications of Electrical Discharge Plasma with Liquid Water-A Mini Review. Int. J. Plasma Environ. Sci. Technol. 2012, 6, 194-203.

6. Chen, Q.; Li, J.; Li, Y. A review of plasma-liquid interactions for nanomaterial synthesis. J. Phys. D Appl. Phys. 2015, $48,424005$. [CrossRef]

7. Machala, Z.; Hensel, K.; Akishev, Y. (Eds.) Plasma for Bio-Decontamination, Medicine and Food Security; NATO Science for Peace and Security Series A: Chemistry and Biology; Springer: Dordrecht, The Netherlands, 2012; ISBN 978-94-007-2851-6.

8. Von Woedtke, T.; Schmidt, A.; Bekeschus, S.; Wende, K.; Weltmann, K.D. Plasma medicine: A field of applied redox biology. In Vivo 2019, 33, 1011-1026. [CrossRef] [PubMed]

9. Vanraes, P.; Bogaerts, A. Plasma physics of liquids-A focused review. Appl. Phys. Rev. 2018, 5, 031103. [CrossRef]

10. Kong, M.G.; Kroesen, G.; Morfill, G.; Nosenko, T.; Shimizu, T.; van Dijk, J.; Zimmermann, J.L. Plasma medicine: An introductory review. New J. Phys. 2009, 11, 115012. [CrossRef]

11. Fridman, G.; Friedman, G.; Gutsol, A.; Shekhter, A.B.; Vasilets, V.N.; Fridman, A. Applied Plasma Medicine. Plasma Process. Polym. 2008, 5, 503-533. [CrossRef]

12. Laroussi, M. Low-Temperature Plasmas for Medicine? IEEE Trans. Plasma Sci. 2009, 37, 714-725. [CrossRef]

13. Šimončicová, J.; Kryštofová, S.; Medvecká, V.; Ďurišová, K.; Kaliňáková, B. Technical applications of plasma treatments: Current state and perspectives. Appl. Microbiol. Biotechnol. 2019, 103, 5117-5129. [CrossRef] [PubMed]

14. Laroussi, M.; Kong, M.; Morfill, G.; Stolz, W. Plasma Medicine: Applications of Low-Temperature Gas Plasmas in Medicine and Biology; Cambridge University Press: Cambridge, UK, 2012; Volume 9781107006, ISBN 9780511902598.

15. Fridman, A.; Friedman, G. Plasma Medicine; John Wiley and Sons: Hoboken, NJ, USA, 2013; ISBN 9780470689707.

16. Fridman, G.; Peddinghaus, M.; Balasubramanian, M.; Ayan, H.; Fridman, A.; Gutsol, A.; Brooks, A. Blood Coagulation and Living Tissue Sterilization by Floating-Electrode Dielectric Barrier Discharge in Air. Plasma Chem. Plasma Process. 2006, 26, 425-442. [CrossRef]

17. Dobrynin, D.; Fridman, G.; Friedman, G.; Fridman, A. Physical and biological mechanisms of direct plasma interaction with living tissue. New J. Phys. 2009, 11, 115020. [CrossRef]

18. Stoffels, E.; Kieft, I.E.; Sladek, R.E.J. Superficial treatment of mammalian cells using plasma needle. J. Phys. D Appl. Phys. 2003, 36, 2908-2913. [CrossRef]

19. Choi, J.; Mohamed, A.-A.H.; Kang, S.K.; Woo, K.C.; Kim, K.T.; Lee, J.K. 900-MHz Nonthermal Atmospheric Pressure Plasma Jet for Biomedical Applications. Plasma Process. Polym. 2010, 7, 258-263. [CrossRef]

20. Lloyd, G.; Friedman, G.; Jafri, S.; Schultz, G.; Fridman, A.; Harding, K. Gas Plasma: Medical Uses and Developments in Wound Care. Plasma Process. Polym. 2010, 7, 194-211. [CrossRef]

21. Kovalóvá, Z.; Zahoran, M.; Zahoranová, A.; Machala, Z. Streptococci biofilm decontamination on teeth by low-temperature air plasma of dc corona discharges. J. Phys. D Appl. Phys. 2014, 47, 224014. [CrossRef]

22. Metelmann, H.R.; von Woedtke, T.; Weltmann, K.D. Comprehensive Clinical Plasma Medicine: Cold Physical Plasma for Medical Application; Springer International Publishing: Berlin/Heidelberg, Germany, 2018; ISBN 9783319676272.

23. Parvulescu, V.I.; Magureanu, M.; Lukes, P. (Eds.) Plasma Chemistry and Catalysis in Gases and Liquids; Wiley-VCH Verlag GmbH \& Co. KGaA: Weinheim, Germany, 2012; ISBN 9783527649525.

24. Puač, N.; Gherardi, M.; Shiratani, M. Plasma agriculture: A rapidly emerging field. Plasma Process. Polym. 2018, 15, 1700174. [CrossRef]

25. Thirumdas, R.; Kothakota, A.; Annapure, U.; Siliveru, K.; Blundell, R.; Gatt, R.; Valdramidis, V.P. Plasma activated water (PAW): Chemistry, physico-chemical properties, applications in food and agriculture. Trends Food Sci. Technol. 2018, 77, 21-31. [CrossRef]

26. Ebihara, K.; Mitsugi, F.; Ikegami, T.; Nakamura, N.; Hashimoto, Y.; Yamashita, Y.; Baba, S.; Stryczewska, H.D.; Pawlat, J.; Teii, S.; et al. Ozone-mist spray sterilization for pest control in agricultural management. Eur. Phys. J. Appl. Phys. 2013, 61, 24318. [CrossRef]

27. Oehmigen, K.; Hähnel, M.; Brandenburg, R.; Wilke, C.; Weltmann, K.-D.; von Woedtke, T. The Role of Acidification for Antimicrobial Activity of Atmospheric Pressure Plasma in Liquids. Plasma Process. Polym. 2010, 7, 250-257. [CrossRef]

28. Graves, D.B. The emerging role of reactive oxygen and nitrogen species in redox biology and some implications for plasma applications to medicine and biology. J. Phys. D Appl. Phys. 2012, 45, 263001. [CrossRef]

29. Brisset, J.L.; Pawlat, J. Chemical Effects of Air Plasma Species on Aqueous Solutes in Direct and Delayed Exposure Modes: Discharge, Post-discharge and Plasma Activated Water. Plasma Chem. Plasma Process. 2016, 36, 355-381. [CrossRef] 
30. Čech, J.; Stahel, P.; Ráhel, J.; Prokeš, L.; Rudolf, P.; Maršálková, E.; Maršálek, B. Mass Production of Plasma Activated Water: Case Studies of Its Biocidal Effect on Algae and Cyanobacteria. Water 2020, 12, 3167. [CrossRef]

31. Machala, Z.; Tarabová, B.; Sersenová, D.; Janda, M.; Hensel, K. Chemical and antibacterial effects of plasma activated water: Correlation with gaseous and aqueous reactive oxygen and nitrogen species, plasma sources and air flow conditions. J. Phys. D Appl. Phys. 2019, 52, 034002. [CrossRef]

32. Machala, Z.; Tarabova, B.; Hensel, K.; Spetlikova, E.; Sikurova, L.; Lukes, P. Formation of ROS and RNS in Water Electro-Sprayed through Transient Spark Discharge in Air and their Bactericidal Effects. Plasma Process. Polym. 2013, 10, 649-659. [CrossRef]

33. Yusupov, M.; Neyts, E.C.; Simon, P.; Berdiyorov, G.; Snoeckx, R.; Van Duin, A.C.T.; Bogaerts, A. Reactive molecular dynamics simulations of oxygen species in a liquid water layer of interest for plasma medicine. J. Phys. D Appl. Phys. 2014, 47. [CrossRef]

34. Stratton, G.R.; Bellona, C.L.; Dai, F.; Holsen, T.M.; Thagard, S.M. Plasma-based water treatment: Conception and application of a new general principle for reactor design. Chem. Eng. J. 2015, 273, 543-550. [CrossRef]

35. Locke, B.R.; Shih, K.Y. Review of the methods to form hydrogen peroxide in electrical discharge plasma with liquid water. Plasma Sources Sci. Technol. 2011, 20, 034006. [CrossRef]

36. Aristova, N.A.; Piskarev, I.M.; Ivanovskii, A.V.; Selemir, V.D.; Spirov, G.M.; Shlepkin, S. Initiation of chemical reactions with an electric discharge in a solid dielectric-gas-liquid system. Russ. J. Phys. Chem. A 2004, 78, 1144-1148.

37. Winter, J.; Tresp, H.; Hammer, M.U.; Iseni, S.; Kupsch, S.; Schmidt-Bleker, A.; Wende, K.; Dünnbier, M.; Masur, K.; Weltmann, K.D.; et al. Tracking plasma generated $\mathrm{H} 2 \mathrm{O} 2$ from gas into liquid phase and revealing its dominant impact on human skin cells. J. Phys. D Appl. Phys. 2014, 47, 285401. [CrossRef]

38. Oinuma, G.; Nayak, G.; Du, Y.; Bruggeman, P.J. Controlled plasma-droplet interactions: A quantitative study of OH transfer in plasma-liquid interaction. Plasma Sources Sci. Technol. 2020, 29, 095002. [CrossRef]

39. Burlica, R.; Grim, R.G.; Shih, K.-Y.; Balkwill, D.; Locke, B.R. Bacteria Inactivation Using Low Power Pulsed Gliding Arc Discharges with Water Spray. Plasma Process. Polym. 2010, 7, 640-649. [CrossRef]

40. Kanev, I.L.; Mikheev, A.Y.; Shlyapnikov, Y.M.; Shlyapnikova, E.A.; Morozova, T.Y.; Morozov, V.N. Are Reactive Oxygen Species Generated in Electrospray at Low Currents? Anal. Chem. 2014, 86, 1511-1517. [CrossRef]

41. Pyrgiotakis, G.; McDevitt, J.; Bordini, A.; Diaz, E.; Molina, R.; Watson, C.; Deloid, G.; Lenard, S.; Fix, N.; Mizuyama, Y.; et al. A chemical free, nanotechnology-based method for airborne bacterial inactivation using engineered water nanostructures. Environ. Sci. Nano 2014, 1, 15-26. [CrossRef]

42. Kovalova, Z.; Leroy, M.; Kirkpatrick, M.J.; Odic, E.; Machala, Z. Corona discharges with water electrospray for Escherichia coli biofilm eradication on a surface. Bioelectrochemistry 2016, 112, 91-99. [CrossRef]

43. Pulicharla, R.; Proulx, F.; Behmel, S.; Sérodes, J.-B.; Rodriguez, M.J. Trends in Ozonation Disinfection By-Products-Occurrence, Analysis and Toxicity of Carboxylic Acids. Water 2020, 12, 756. [CrossRef]

44. Ferreiro, C.; Villota, N.; Lombraña, J.I.; Rivero, M.J. Heterogeneous Catalytic Ozonation of Aniline-Contaminated Waters: A Three-Phase Modelling Approach Using $\mathrm{TiO}_{2} / \mathrm{GAC}$. Water 2020, 12, 3448. [CrossRef]

45. Berry, M.; Taylor, C.; King, W.; Chew, Y.; Wenk, J. Modelling of Ozone Mass-Transfer through Non-Porous Membranes for Water Treatment. Water 2017, 9, 452. [CrossRef]

46. Xia, Z.; Hu, L. Treatment of Organics Contaminated Wastewater by Ozone Micro-Nano-Bubbles. Water 2018, 11, 55. [CrossRef]

47. Grace, J.M.; Marijnissen, J.C.M. A review of liquid atomization by electrical means. J. Aerosol Sci. 1994, 25, 1005-1019. [CrossRef]

48. Borra, J.P.; Ehouarn, P.; Boulaud, D. Electrohydrodynamic atomisation of water stabilised by glow discharge-Operating range and droplet properties. J. Aerosol Sci. 2004, 35, 1313-1332. [CrossRef]

49. Pongrác, B.; Kim, H.H.; Janda, M.; Martišovitš, V.; Machala, Z. Fast imaging of intermittent electrospraying of water with positive corona discharge. J. Phys. D Appl. Phys. 2014, 47, 315202. [CrossRef]

50. Jaworek, A.; Sobczyk, A.; Czech, T.; Krupa, A. Corona discharge in electrospraying. J. Electrostat. 2014, 72, 166-178. [CrossRef]

51. Maguire, P.D.; Mahony, C.M.O.; Kelsey, C.P.; Bingham, A.J.; Montgomery, E.P.; Bennet, E.D.; Potts, H.E.; Rutherford, D.C.E.; McDowell, D.A.; Diver, D.A.; et al. Controlled microdroplet transport in an atmospheric pressure microplasma. Appl. Phys. Lett. 2015, 106, 224101. [CrossRef]

52. Jaworek, A.; Ganán-Calvo, A.M.; Machala, Z. Low temperature plasmas and electrosprays. J. Phys. D Appl. Phys. 2019, 52, 233001. [CrossRef]

53. Borra, J.-P. Review on water electro-sprays and applications of charged drops with focus on the corona-assisted cone-jet mode for High Efficiency Air Filtration by wet electro-scrubbing of aerosols. J. Aerosol Sci. 2018, 125, 208-236. [CrossRef]

54. Stancampiano, A.; Gallingani, T.; Gherardi, M.; Machala, Z.; Maguire, P.; Colombo, V.; Pouvesle, J.-M.; Robert, E. Plasma and Aerosols: Challenges, Opportunities and Perspectives. Appl. Sci. 2019, 9, 3861. [CrossRef]

55. Sander, R. Compilation of Henry's law coefficients (version 4.0) for water as solvent. Atmos. Chem. Phys. 2015, 15, 4399-4981. [CrossRef]

56. Kruszelnicki, J.; Lietz, A.M.; Kushner, M.J. Interaction between atmospheric pressure plasmas and liquid microdroplets. In Proceedings of the International Conference on Plasmas with Liquids (ICPL 2017), Prague, Czech Republic, 5-9 March 2017; Lukeš, P., Koláček, K., Eds.; p. 37.

57. Kruszelnicki, J.; Lietz, A.M.; Kushner, M.J. Atmospheric pressure plasma activation of water droplets. J. Phys. D Appl. Phys. 2019, 52, 355207. [CrossRef] 
58. Verlackt, C.C.W.; Van Boxem, W.; Bogaerts, A. Transport and accumulation of plasma generated species in aqueous solution. Phys. Chem. Chem. Phys. 2018, 20, 6845-6859. [CrossRef] [PubMed]

59. Eisenberg, G.M. Colorimetric Determination of Hydrogen Peroxide. Ind. Eng. Chem. Anal. Ed. 1943, 15, 327-328. [CrossRef]

60. Bader, H.; Hoigné, J. Determination of ozone in water by the indigo method. Water Res. 1981, 15, 449-456. [CrossRef]

61. Tarabová, B.; Lukeš, P.; Janda, M.; Hensel, K.; Šikurová, L.; Machala, Z. Specificity of detection methods of nitrites and ozone in aqueous solutions activated by air plasma. Plasma Process. Polym. 2018, 15, 1800030. [CrossRef]

62. Carey, V.P. Liquid-Vapor Phase-Change Phenomena; CRC Press: Boca Raton, FL, USA, 2020.

63. Garrett, B.C.; Schenter, G.K.; Morita, A. Molecular simulations of the transport of molecules across the liquid/vapor interface of water. Chem. Rev. 2006, 106, 1355-1374. [CrossRef]

64. Garrett, B.C. Ions at the Air/Water Interface. Science 2004, 303, 1146-1147. [CrossRef]

65. Morita, A.; Garrett, B.C. Molecular theory of mass transfer kinetics and dynamics at gas-water interface. Fluid Dyn. Res. 2008, 40, 459-473. [CrossRef]

66. Johnson, P.N.; Davis, R.A. Diffusivity of ozone in water. J. Chem. Eng. Data 1996, 41, 1485-1487. [CrossRef] 